\title{
DIPLOMACIA ECONÓMICA Y BALANZA DE PAGOS. LOS PACTOS HISPANO-ESTADOUNIDENSES DE 1918 *
}

\author{
JOSÉ ANTONIO MONTERO JIMÉNEZ
}

Georgetown University ${ }^{\text {a }}$

\section{RESUMEN}

Este artículo examina las conexiones existentes entre la evolución de la balanza de pagos española y la diplomacia económica hispano-estadounidense a lo largo de 1917 y 1918. El devenir de estas relaciones puede servir para explicar una parte sustancial de la desaceleración del comercio exterior de España que tuvo lugar en el último año de la Primera Guerra Mundial. El endurecimiento de la política comercial de los Estados Unidos tras su entrada en la contienda obligó a los españoles a trabajar seriamente para mantener tanto el nivel de sus intercambios mercantiles como la libertad de su marina mercante. Los contactos entre los dos países afectaron igualmente al proceso de repatriación de la deuda externa de España y al uso de sus beneficios extraordinarios para efectuar préstamos a las naciones aliadas. Finalmente, las negociaciones bilaterales produjeron la firma de dos acuerdos bilaterales en marzo y agosto de 1918, cuya gestación y repercusiones pueden seguirse a través de las cifras mensuales del comercio entre Norteamérica y la Península Ibérica.

Received 02/26/2008. Accepted 05/22/2008. El autor desea agradecer la colaboración y los consejos de Albert Carreras, Antonio Niño, Núria Puig y los evaluadores anónimos de RHE. Por otra parte, la realización de este artículo ha sido posible gracias a la ayuda del programa de becas postdoctorales del Ministerio de Educación y Ciencia.

a Prince of Asturias Chair / BMW Center for German and European Studies, $37^{\text {th }}$ and O Streets, NW, ICC 501, Washington DC, 20057. jam286@georgetown.edu. 
Palabras clave: Primera Guerra Mundial, diplomacia económica, España, Estados Unidos

Economic diplomacy and the balance of payments. The 1918 Spanish-American pacts

\begin{abstract}
This paper studies the links between the evolution of Spain's balance of payments and Spanish-American economic diplomacy along 1917 and 1918. The development of these relations may be useful to explain a great deal about the downturn in Spanish foreign commerce during the last year of WWI. After their entrance into the conflict, the United States toughened their commercial policies and made the Spaniards work hard to keep both their international trade and the freedom of their merchant marine. Contacts between the two countries dealt also with the repatriation of Spain's foreign debt and the use of its extraordinary profits to make loans to the Allied nations. The negotiations ended up in March and August, 1918 with the signing of two bilateral agreements, whose consequences can be followed using the monthly figures of trade between America and the Iberian Peninsula.
\end{abstract}

Keywords: World War I, economic diplomacy, Spain, United States

JEL Classification: N42, N44, N72, N74

\title{
1. INTRODUCCIÓN
}

Las consecuencias de la Gran Guerra para la economía española han sido objeto de atención preferencial por parte de diversos estudiosos desde el mismo momento en que finalizó la contienda. Dentro del ámbito diplomático, algunas grandes potencias desearon conocer de manera precisa las repercusiones que las circunstancias excepcionales del cuatrienio 19141918 habían tenido sobre sus intereses en la Península Ibérica. En este punto resultaron especialmente activos los Estados Unidos, cuyo Departamento de Comercio inició una campaña para sondear las posibilidades comerciales y de inversión que ofrecía la Europa posbélica. Así, en la primavera de 1919 se produjo el nombramiento de un Agregado Comercial permanente en la Embajada de Madrid, y se comisionó al economista y abogado Arthur N. Young para realizar un estudio exhaustivo de las condiciones mercantiles y financieras de España. Fruto de las pesquisas de este antiguo profesor de Princeton fue la publicación de un trabajo donde precisaba la mayor parte de los desafíos que habrían de afrontar en años posteriores los historiadores económicos españoles interesados en el período bélico. 
Como no podía ser menos, Young (1920, pp. 69-101) llamó la atención sobre los beneficios en la balanza de pagos española, fruto de los saldos positivos en los intercambios comerciales, las ganancias obtenidas por los navieros españoles dedicados al transporte de mercancías y las remesas de los ciudadanos españoles que se desplazaron temporalmente a Francia para suplir las demandas de mano de obra emanadas del gobierno galo. Estos beneficios permitieron la acumulación de grandes reservas de oro por parte del Banco de España, la repatriación de una parte importante de la deuda pública hispana custodiada por manos extranjeras e incluso la concesión de créditos a Francia, Gran Bretaña y Norteamérica. Todo lo cual condujo a su vez a una apreciación de la peseta con respecto a las divisas de las principales naciones beligerantes. Sin embargo, aunque el autor fue capaz de resaltar todos estos procesos, e incluso de cifrar los dividendos españoles en 3.600 millones de pesetas, hubo de admitir las enormes dificultades que existían para cuantificarlos de manera exacta. Una realidad derivada de los defectos de forma que aquejaban a las estadísticas oficiales españolas.

Los primeros esfuerzos para corregir estas trabas se centraron en las series de importaciones y exportaciones aparecidas en la Estadística General del Comercio Exterior. Éstas se efectuaban en función de una lista de precios que para las distintas mercancías emitía la Junta de Valoraciones, y que no sufrió ninguna modificación entre los años 1912 y 1921. De esta manera, las cifras oficiales dejaron de registrar las importantes variaciones en el valor de los productos acaecidas durante la guerra. Uno de los primeros en tratar de solventar este problema fue Juan Antonio Vandellós (1931), quien ya en 1931 publicó una estimación corregida de los intercambios mercantiles españoles. Su testigo fue recogido a lo largo de las siguientes décadas por diversos autores, hasta que en los años noventa del pasado siglo Antonio Tena (1992) y Carles Sudrià (1990) obtuvieron resultados muy precisos mediante la aplicación de una técnica similar a la empleada por Leandro Prados para el siglo XIX. Respecto a los otros problemas apuntados por Young, acapararon el interés de diferentes expertos a partir de la década de 1970. José Luis GarcíaDelgado y Santiago Roldán ofrecieron en 1973 una relación del precio de los fletes a lo largo de la Gran Guerra. Asimismo, el francés Albert Broder (1981, pp. 633-643) efectuó en su tesis de estado un repaso del proceso de nacionalización de la deuda exterior española en manos de inversores extranjeros ${ }^{1}$.

La cuantificación de estos procesos planteó algunos interrogantes que estimularon a su vez la aplicación de nuevos enfoques. Uno de ellos se centró en analizar las conexiones entre la evolución de la balanza de pagos y la acción de las autoridades gubernamentales. Desde este punto de vista, Elena San Román hizo especial hincapié en la amenaza de sufrir una crisis de abastecimientos que se cernió sobre España como consecuencia del con-

${ }^{1} C f r$. igualmente, Tena (1985 y 2005). Una explicación sobre los errores de las valoraciones en Tena (1992, pp. 31-36). 
flicto. El cierre de muchos de los mercados donde el país adquiría materias primas y productos de primera necesidad imprescindibles para el funcionamiento de su economía convirtió la búsqueda de nuevas fuentes de abasto en una tarea inevitable a la par que complicada. Algo que llevó a diversos sectores de la oficialidad española a sentirse especialmente agraviados por esta dependencia del exterior, y a optar por la promoción de vías autárquicas capaces de proteger a España ante futuras amenazas exteriores ${ }^{2}$.

Ahora bien, es posible dar la vuelta al argumento de San Román, y estudiar no sólo las lecciones que la clase dirigente extrajo del devenir de la balanza de pagos, sino también la medida en que ésta se vio influida por las decisiones de los gobiernos. Tal perspectiva puede resultar útil para dar cuenta de lo que Carles Sudrià (1990, p. 371) ha denominado el "paréntesis de 1918». En ese año se vio interrumpida la tendencia al alza que venía definiendo el comercio exterior de España, produciéndose un brusco descenso

CUADRO 1

COMERCIO EXTERIOR DE ESPAÑA CON SUS PRINCIPALES SOCIOS (1914-1918)

(Cifras en millones de pesetas)

\begin{tabular}{|c|c|c|c|c|c|c|c|c|c|}
\hline & 1914 & $\%$ & 1915 & $\%$ & 1916 & $\%$ & 1917 & $\%$ & 1918 \\
\hline $\begin{array}{l}\text { General } \\
\text { Importaciones } \\
\text { Exportaciones } \\
\text { Saldo } \\
\end{array}$ & $\begin{array}{r}1.084,3 \\
1.089,8 \\
5,5 \\
\end{array}$ & & $\begin{array}{r}1.145,4 \\
1.488,8 \\
343,4 \\
\end{array}$ & & $\begin{array}{r}1.581,8 \\
1.887,2 \\
305,4 \\
\end{array}$ & & $\begin{array}{r}1.517,6 \\
1.934,2 \\
416,6 \\
\end{array}$ & & $\begin{array}{r}1.314,2 \\
1.382,3 \\
68,1 \\
\end{array}$ \\
\hline $\begin{array}{l}\text { Gran Bretaña } \\
\text { Importaciones } \\
\text { Exportaciones } \\
\text { Saldo } \\
\end{array}$ & $\begin{array}{l}222,6 \\
355,8 \\
133,2 \\
\end{array}$ & $\begin{array}{l}20,5 \\
32,7\end{array}$ & $\begin{array}{l}236,1 \\
404,8 \\
168,7\end{array}$ & $\begin{array}{l}20,6 \\
27,2\end{array}$ & $\begin{array}{l}334,5 \\
454,0 \\
119,5 \\
\end{array}$ & $\begin{array}{l}29,2 \\
24,1\end{array}$ & $\begin{array}{r}215,8 \\
218,6 \\
2,8 \\
\end{array}$ & $\begin{array}{l}18,8 \\
11,3\end{array}$ & $\begin{array}{l}193,3 \\
330,0 \\
136,7 \\
\end{array}$ \\
\hline $\begin{array}{l}\text { Francia } \\
\text { Importaciones } \\
\text { Exportaciones } \\
\text { Saldo }\end{array}$ & $\begin{array}{r}119,9 \\
197,8 \\
77,9\end{array}$ & $\begin{array}{l}11,1 \\
18,2\end{array}$ & $\begin{array}{l}133,7 \\
532,3 \\
398,6\end{array}$ & $\begin{array}{r}11,7 \\
35,8\end{array}$ & $\begin{array}{l}167,2 \\
723,5 \\
556,3\end{array}$ & $\begin{array}{l}14,6 \\
38,3\end{array}$ & $\begin{array}{l}167,4 \\
988,0 \\
820,6\end{array}$ & $\begin{array}{l}14,6 \\
51,1\end{array}$ & $\begin{array}{l}141,6 \\
412,0 \\
270,4\end{array}$ \\
\hline $\begin{array}{c}\text { Estados Unidos } \\
\text { Importaciones } \\
\text { Exportaciones } \\
\text { Saldo }\end{array}$ & $\begin{array}{l}152,6 \\
109,6 \\
-43,0\end{array}$ & $\begin{array}{l}14,1 \\
10,1\end{array}$ & $\begin{array}{r}284,3 \\
88,1 \\
-196,2\end{array}$ & $\begin{array}{r}24,8 \\
5,9\end{array}$ & $\begin{array}{r}399,2 \\
135,4 \\
-263,8\end{array}$ & $\begin{array}{r}34,9 \\
7,2\end{array}$ & $\begin{array}{r}516,7 \\
136,3 \\
-380,4\end{array}$ & $\begin{array}{r}45,1 \\
7,1\end{array}$ & $\begin{array}{r}322,5 \\
64,5 \\
-258,0\end{array}$ \\
\hline $\begin{array}{l}\text { Argentina } \\
\text { Importaciones } \\
\text { Exportaciones } \\
\text { Saldo }\end{array}$ & $\begin{array}{l}23,2 \\
50,6 \\
27,4\end{array}$ & $\begin{array}{l}2,1 \\
4,6\end{array}$ & $\begin{array}{r}65,2 \\
73,5 \\
8,3\end{array}$ & $\begin{array}{l}5,7 \\
4,9\end{array}$ & $\begin{array}{l}89,4 \\
87,4 \\
-2,0\end{array}$ & $\begin{array}{l}7,8 \\
4,6\end{array}$ & $\begin{array}{r}63,8 \\
109,7 \\
45,9\end{array}$ & $\begin{array}{l}5,6 \\
5,7\end{array}$ & $\begin{array}{r}119,3 \\
147,3 \\
28,0\end{array}$ \\
\hline
\end{tabular}

Fuente: Sudrià (1990).

${ }^{2}$ La influencia de la Gran Guerra en la organización económica de diversos países fue contemplada en San Román (1994). Para el caso español, cfr. San Román (1999). 
en el nivel de intercambios (cuadro 1). De hecho, la mayor parte de los autores que contribuyeron a la corrección de las cifras comerciales se mostraron intrigados por la desaceleración acaecida en este año. Sus cálculos acabaron demostrando que una parte de la bajada reflejada en las estadísticas era fruto de la falta de actualización de las valoraciones. Sin embargo, las estimaciones seguían mostrando un significativo declive, hasta ahora poco explicado, pero que puede seguirse en gran medida a través del análisis de la diplomacia económica hispano-estadounidense a lo largo de 1917 y 1918. La intensa red de contactos que se estableció entonces entre las autoridades estadounidenses y españolas fue más allá de las dinámicas puramente comerciales, afectando a la mayor parte de los problemas ya citados: la repatriación de los títulos de la deuda extranjera, la revalorización de la peseta frente a las divisas aliadas, la situación de la marina mercante española, la constatación de la debilidad en que sumía a España su dependencia de los mercados exteriores, etc. De tal forma, a lo largo de las páginas que siguen trataremos de establecer una conexión directa entre las variaciones acaecidas en la balanza de pagos y los avatares de la relación entre España y los Estados Unidos en los últimos meses de la Gran Guerra. Unos contactos cuyos hitos más destacados fueron la firma de un convenio comercial y otro financiero en marzo y agosto de 1918.

\section{LOS ESTADOS UNIDOS DE LA NEUTRALIDAD A LA BELIGERANCIA}

Los Estados Unidos vieron el estallido de la Primera Guerra Mundial como una oportunidad de aprovechar la momentánea debilidad de los beligerantes europeos para introducirse en mercados que hasta entonces contaban con una escasa presencia norteamericana. Por su parte, desde el mismo verano de 1914 España fue consciente de la imposibilidad de arbitrar una política de sustitución de importaciones lo suficientemente amplia como para cubrir las necesidades que su industria tenía de las materias primas y fuentes de energía del exterior. La alteración de los mercados europeos como consecuencia del conflicto no dejó a los españoles otra opción que buscar una parte importante de esos productos que precisaban al otro lado del Atlántico. De esta manera, los proyectos de expansión norteamericanos se coaligaron con las necesidades españolas para producir un más que significativo aumento del tráfico comercial hispano-estadounidense.

La característica más sobresaliente de estos intercambios fue su desigualdad, ya que las ventas de Norteamérica hacia España crecieron en mucha mayor medida — de 27.815.504 dólares en 1914 a 91.584.080 dólares en 1917-que las compras estadounidenses de mercaderías españolas — de 22.041.006 dólares a 36.881.630 en el mismo período-. De igual manera, las mercancías adquiridas por España —algodón, harina, petróleo, metales, 
maquinaria, etc.- eran comparativamente más relevantes que las enviadas por ésta a los Estados Unidos — corcho, pieles, almendras,...- - Un indicador de este creciente papel de Norteamérica en el comercio exterior español vino determinado por el menor peso del algodón en los intercambios bilaterales. En el año fiscal 1913-1914, esta fibra representó el 64 por cien de las importaciones hispanas provenientes de los Estados Unidos; a la altura de 19151916, ese porcentaje había descendido al 39 por cien, a pesar de que el volumen total del algodón norteamericano desembarcado en la Península creció de 285.158 balas a 319.309 durante el mismo período. Este cambio fue consecuencia directa del aumento en las adquisiciones de otros productos básicos, tales como el trigo — 0 por cien en 1913-1914 y 13,3 por cien en 19151916—, los productos químicos — 0,4 y 4,7 por cien-, el cobre $-0,2$ y 9,8 por cien- o el azúcar - 0 y 2,5 por cien—. España pasó así a depender seriamente del flujo comercial proveniente de Norteamérica, que a la altura de 1917 era la principal proveedora del país, con una cuota de más del 45 por cien de las importaciones. No obstante, el déficit de la balanza comercial hispano-norteamericana se solventó sobradamente con las cuantiosas ventas efectuadas por los españoles a Francia y Gran Bretaña. Sin embargo, este delicado equilibrio entre el lucrativo comercio con los aliados y las necesarias compras a Norteamérica dependía de la continuidad de un factor que muchos daban por inamovible: la apertura del mercado estadounidense ${ }^{3}$.

El panorama cambió significativamente una vez que los Estados Unidos declararon la guerra a Alemania en abril de 1917. Es cierto que en un principio Washington reafirmó su determinación de no utilizar contra los neutrales armas de presión como las esgrimidas por Francia o Gran Bretaña: «las bases de la cooperación de los Estados Unidos [con la Entente] no pasan por ayudar en el bloqueo de los países neutrales, ni por tomar parte en otras medidas de los aliados que los Estados Unidos han visto hasta ahora como ajenas a la ley internacional». Sin embargo, esta determinación inicial se desvaneció a lo largo de unas pocas semanas, como consecuencia de tres factores: los rigores que la contienda estaba ocasionando en el devenir interno estadounidense; las presiones de los aliados; y las necesidades logísticas de las primeras unidades del ejército norteamericano destacadas en Francia. Al objeto de garantizar el perfecto desarrollo de la maquinaria militar, los dirigentes estadounidenses se vieron poco a poco forzados a suspender la vigencia de algunos de los principios que habían guiado hasta entonces su actuación en el campo económico. El gobierno sustituyó su tradicional apego a las doctrinas del laissez faire por un estricto control de la producción industrial, así como de los medios de transporte terrestres y marítimos. Ante esta realidad, no tardó en difundirse entre diversos secto-

3 Department of Commerce (1917 y 1920). "Annual Report of Commerce and Industries», 20/5/1920. National Archives and Records Administration (NARA), Record Group (RG) 84, Embassy Madrid, 1920. 
res la opinión de que los neutrales debían compartir una parte de la carga que ahora recaía sobre los ciudadanos estadounidenses ${ }^{4}$.

Por otra parte, Francia y Gran Bretaña trabajaron desde muy pronto para que Norteamérica accediera a coordinar con ellos su actuación hacia los neutrales. En la primavera de 1917 desembarcó en los Estados Unidos una misión inglesa presidida por el Secretario de Exteriores británico, Arthur James Balfour. Entre sus propuestas destacó un programa común de política comercial basado en la restricción de las exportaciones norteamericanas. Los Estados Unidos deberían embargar todo su comercio exterior y establecer un sistema de licencias de exportación para regular la salida de cualquier mercancía. Los ingleses constataron que «los Estados Unidos [...] son, de hecho, productores de materiales sin los cuales [los neutrales...] ni pueden mantener su agricultura ni su acumulación de reservas». De esta manera, Washington podría condicionar la concesión de permisos de exportación hacia naciones neutrales a la aquiescencia por parte de éstas para prestar algún tipo de servicio a la causa aliada ${ }^{5}$.

Tales previsiones se acompañaron muy pronto de planes concretos en relación con España. En mayo de 1917 el propio Balfour escribió al Secretario de Estado, Robert Lansing, pidiéndole ayuda para lograr la ratificación de un acuerdo comercial que había negociado en Londres el Marqués de Cortina, actuando en nombre del gobierno español presidido por el Conde de Romanones. El convenio daba permiso a España para importar 150.000 toneladas de carbón inglés a cambio de no poner trabas a la salida hacia Inglaterra del hierro hispano y de permitir a los británicos el uso de mercantes españoles hasta un total de 400.000 toneladas. No obstante, Javier García Prieto, que sustituyó a Romanones en la jefatura del gabinete, no pareció ver con muy buenos ojos este arreglo y decidió paralizar su ratificación. Hasta ese momento, España había seguido teniendo a Gran Bretaña como principal proveedora de carbón, a pesar de que las importaciones españolas de hulla norteamericana habían pasado de 42.875 toneladas en el año fiscal 1913-1914 a 209.712 en 1916-1917. Londres comenzó entonces a temer que España estuviese tratando de sustituir definitivamente el mineral británico con el estadounidense, privando eventualmente a Inglaterra de las importantes contrapartidas en hierro y tonelaje peninsulares. Para evitarlo, el Foreign Office recomendó al Secretario de Estado que «indicase al Gobierno español [...] que está en completo acuerdo con los puntos de vista del Gobierno británico [y que...] los Estados

4 Memorando del Consejero Legal del Departamento de Estado, 17/5/1917. Papers Relating to the Foreign Relations of the United States (FRUS), 1917, Suppl. 2, vol. II, pp. 865-870. Kennedy (1980), Kaufman (1974), Bailey (1966, pp. 35-40) y Woolsey (1917).

5 Desp. 5.449, de Sharp a Lansing, 11/6/1917; desp. 5.421, de Sharp a Lansing, 4/5/1917; Memorando de la Embajada británica al Secretario de Estado, 7/5/1917. FRUS, 1917, Suppl. 2, vol. II, pp. 865-870. Bailey (1934). Un estudio exhaustivo de los resultados de esta política de coordinación entre los aliados y Norteamérica en Davis y Engerman (2006, pp. 159-237). 
Unidos no veían la posibilidad de permitir la exportación de carbón a España, toda vez que había obtenido del Reino Unido una amplia provisión del mismo». Un ruego que Washington se apresuró a cumplir ${ }^{6}$.

La situación del ejército norteamericano estacionado en Francia resultó otro poderoso factor a la hora del redefinir la política de Washington. Desde la llegada de la primera división norteamericana a territorio galo el número de soldados estadounidenses sirviendo bajo las órdenes del general John J. Pershing no paró de aumentar. Pronto se hicieron patentes a los organizadores norteamericanos las enormes dificultades que implicaban la alimentación y el abastecimiento de una fuerza de gran magnitud. El encargado de lidiar con estas trabas, en su calidad de Agente General de Compras, fue el Teniente Coronel Charles Gates Dawes, antiguo presidente del Central Trust Bank de Illinois y futuro artífice del famoso Plan Dawes de 1924. Aprovechándose de la experiencia de sus colegas ingleses y franceses, el Agente de Compras concibió para sus tropas un método de abastos que reservaba un papel fundamental a la Península Ibérica: los Estados Unidos podrían aprovecharse de las necesidades hispanas de petróleo y algodón para obligar a Madrid a vender todo aquello que precisasen las huestes norteamericanas. Para estudiar sobre el terreno las posibilidades de este esquema, Dawes envió en octubre a la Península a John R. Christie, quien hasta hacía poco había dirigido la sucursal española de la New York Life Insurance Company. En su informe, Christie corroboró que España conformaba un excelente mercado para obtener "grano, verduras, textiles, vinos, minerales, metales, piritas, carbón vegetal, traviesas de ferrocarril, madera [y] materiales de construcción». Por su parte, los españoles precisaban urgentemente «algodón, aceites lubricantes, petróleo, grasas, carbón, fosfatos, yute, maquinaria y, en particular, recambios para la reparación de motores de ferrocarril». Sobre esta base, el empleado de la New York recomendaba la negociación de un acuerdo comercial hispano-norteamericano: «no se pueden realizar compras de importancia para la American Expeditionary Force (AEF), a no ser que el gobierno de Washington se ponga de acuerdo con el gobierno español para que América dé vía libre a los materiales que España precisa con urgencia, y por otro lado, España acceda a levantar su embargo [...]. Sin tal quid pro quo las mercancías que podamos obtener serán de escasa utilidad para el ejército" ${ }^{7}$.

La interiorización de estas realidades fue llevando a los Estados Unidos hacia el arbitraje de actuaciones que endurecieron significativamente su política comercial hacia los neutrales. Este proceso se desarrolló en dos

${ }^{6}$ Department of Commerce (1917). Carta de Balfour a Lansing, 5/5/1917. FRUS, 1917, Suppl. 2, vol. II, pp. 1.199-1.202. Desp. 950, de Ch. S. Wilson a Lansing, 23/11/1917. NARA, RG 84, Embassy Madrid, 1917.

${ }^{7}$ Ferro (1994, p. 230), Bliven (1928) y Goedeken (1986). Tel. 2.607, de Sharp a Lansing, 16/10/1917 e Informe de Christie, 3/1/1918. NARA, RG 59, 1910-1929, 652.119/136 y 455. Sobre la New York Life en España, cfr. NARA, RG 59, 1910-1929, 852.5064. 
vertientes bien diferenciadas: una interna, materializada en la batería de medidas legales destinadas a controlar los intercambios mercantiles mientras durase la guerra; y otra externa, basada en el reforzamiento de la colaboración con la Entente en materia comercial y financiera. El primer proceso vino marcado por la aprobación, el 15 de junio de 1917, de la Ley de Espionaje, cuyo título VI, sección 1, daba al Presidente autoridad discrecional para declarar «ilegal la exportación o el embarque o la salida de los Estados Unidos [...] de algún artículo». Poco después, el 22 de ese mes, se creó el Exports Council, integrado por los Secretarios de Estado, Agricultura y Comercio, así como por el Administrador de Alimentos. Sus labores se ceñirían a «formular, para la consideración y aprobación del Presidente, $[. .$.$] recomendaciones necesarias con vistas a llevar adelante los$ propósitos» de la Espionage Act. Profundizando en la misma tendencia, el 9 de julio Woodrow Wilson decretó un primer embargo que afectaba a diversos productos alimenticios — como el trigo-, minerales combustibles — carbón, petróleo,...-, metales - hierro, acero, etc.— armas y municiones. La medida incumbía a varios países neutrales, entre los que España aparecía citada de forma expresa ${ }^{8}$.

Para la ejecución y administración de estas restricciones comerciales fue instituido, un mes y medio después, el Exports Administrative Board, integrado a su vez por los Secretarios de Estado, Agricultura y Comercio, el Administrador de Alimentos y el Consejo de Navegación. Casi a la par, el 27 de agosto, se promulgó un segundo embargo que incluía prácticamente todos los productos susceptibles de intercambio internacional, así como la exportación de moneda y metales preciosos. La piedra angular de todo este montaje vino dada por la formación, el 12 de octubre de 1917, del War Trade Board (WTB), llamado a sustituir al Exports Adminitrative Board, compuesto por los mismos organismos que éste, y dirigido por un político demócrata originario de Pennsylvania: Vance Criswell McCormick. Con el WTB se asentaron definitivamente los cimientos de una potentísima maquinaria mercantil dedicada a filtrar exhaustiva y sistemáticamente la concesión de licencias de exportación para productos embargados. Algo que fue posible gracias a la instauración de una considerable red de delegaciones, ubicadas por igual en países neutrales y beligerantes. Con todo, esta batería de medidas legales no impidió que los neutrales pudieran seguir recibiendo mercancías embargadas, pero para hacerlo el Board les tenía que otorgar la correspondiente licencia de exportación. Quedaba así en manos de Washington la capacidad de cortar las exportaciones hacia cualquier nación no beligerante sobre la que los Estados Unidos decidiesen ejercer algún tipo de presión ${ }^{9}$.

8 «Espionage Act», 15/6/1917. Executive Order 2.645, 22/6/1917; Proclamación 1385, 9/7/1917. FRUS, 1917, Suppl. 2, vol. II, pp. 883-884 y 903-905.

9 Proclamación 2.687, 21/8/1917; Proclamación 1.391, 27/8/1917; la constitución del WTB en Orden Ejecutiva 2.769, 12/10/1917. FRUS, ibid., pp. 926-927, 933-937 y 963-970. 
La coordinación con Francia y Gran Bretaña se discutió en la Conferencia Interaliada celebrada en París entre el 29 de noviembre y el 9 de diciembre de 1917. Sus intervinientes dividieron el trabajo entre varios Comités, algunos de los cuales se encargaron de definir diferentes aspectos de la política comercial aliada hacia España. Uno de ellos fue el Comité de Bloqueo, donde los norteamericanos estuvieron representados por Vance McCormick, y ante el que Charles G. Dawes tuvo ocasión de exponer sus ideas. Entre sus disposiciones finales, Bloqueo contempló «la creación de un Comité Conjunto de Compras para los Aliados, que eliminaría la competencia de las ofertas». Asimismo, se acordó estudiar concienzudamente los embargos que sobre la venta al exterior de algunos de sus productos tenía dictados el ejecutivo español, para «si los Gobiernos aliados están siendo discriminados [...] recomendar un sistema de represalias centrado en el rechazo de licencias para la exportación desde América del algodón y el combustible». Por otra parte, el Comité de Transporte Marítimo, donde actuó como delegado norteamericano el futuro Secretario de Estado Bainbridge Colby, lidió con el posible uso del tonelaje neutral para cubrir las necesidades de transporte aliadas. A esas alturas era ya una política establecida del WTB «buscar algunas concesiones de tonelaje como compensación a la relajación del embargo sobre determinadas exportaciones». Así pues, no resultó extraño que la Conferencia acordase oficialmente la utilización de las restricciones comerciales de los Estados Unidos como instrumento coactivo para forzar a los no beligerantes a poner algunos de sus barcos a disposición de las potencias occidentales ${ }^{10}$.

\section{EL CONVENIO COMERCIAL DE MARZO DE 1918}

A mediados de 1917, la situación económica de España estaba dando muestras de sufrir algunas fisuras. La escasez de determinados productos básicos había provocado una pronunciada elevación de los precios - desde un índice del 99,7 por cien en 1914 a otro del 150,1 por cien en 1917 $(100=1913)$ - que estuvo en el corazón del movimiento huelguístico de agosto de ese año. A la hora de buscar las causas de la inflación se apuntó directamente a dos fenómenos íntimamente relacionados con el comercio exterior: la retirada del mercado nacional de una parte de la producción española cuya venta resultaba más rentable en el extranjero; y los obstáculos que existían para la importación de determinadas mercancías consideradas como imprescindibles. En este marco, las autoridades españolas se dieron cuenta muy pronto de las implicaciones que la beligerancia norteamericana tendría para la estabilidad mercantil del país. En marzo de

${ }^{10}$ Informe de McCormick; Informe de Colby. FRUS, 1917, Suppl. 2, vol I, pp. 400-409 y 409-423. 
1917, el Embajador de España en Washington, Juan Riaño, escribió a sus superiores que si los Estados Unidos adquirían la obligación de surtir de vituallas, así como de materias primas, a sus aliados y a Latinoamérica, «poco quedaría disponible para los neutrales». El gobierno español trató entonces de evitar que las restricciones comerciales emanadas de Washington se aplicasen a la Península Ibérica. Para ello se valió de dos argumentos que fueron presentados directamente ante la diplomacia y la opinión pública norteamericanas. En primer lugar, el Ministerio de Estado trató de hacer ver que España no necesitaba incentivos para decantar sus intercambios hacia el bando aliado, ya que tanto la geografía como el bloqueo británico del Mar del Norte le impedían tener tratos comerciales directos con Alemania. En segundo lugar, después de noviembre de 1917 el ejecutivo español no cesó de exhibir ante las Potencias Occidentales una especie de fantasma revolucionario: si España se veía sometida a un bloqueo capaz de desencadenar una crisis industrial, «era de temer una revolución que podía poner en peligro la monarquía española» y convertir a la nación en una nueva Rusia ${ }^{11}$.

Sin embargo, las súplicas de España no impidieron que ésta se viese privada poco a poco de los productos más relevantes de su comercio con los Estados Unidos. El embargo del 26 de julio cortó la salida libre de carbón norteamericano, afectando primordialmente a los barcos españoles anclados en puertos estadounidenses. Éstos debían solicitar al WTB permiso con vistas a cargar el carbón necesario para el viaje de vuelta, algo que ralentizaba considerablemente la salida de navíos. Así, si en julio la capacidad de carga de las embarcaciones destinadas a la Península había ascendido a 57.418 toneladas, en agosto fue de tan sólo 40.280, en septiembre de 36.396, en octubre de 39.600 y en noviembre de 33.797 (cuadro 2). Asimismo, ante el rumor de que algunos españoles estaban utilizando parte del combustible estadounidense para abastecer a los submarinos alemanes, el Exports Administrative Board decidió interrumpir en octubre la concesión de licencias para exportar petróleo a la Península. Esta prohibición tardó algún tiempo en hacerse efectiva, ya que en ese mes las exportaciones de este mineral hacia España todavía fueron de 54.005 galones, que bajaron a 9.330 en noviembre para desaparecer definitivamente al mes siguiente (cuadro A-1). Por su parte, el comercio de algodón continuó libremente durante unas semanas más, debido fundamentalmente a las presiones ejercidas sobre el Departamento de Estado por los productores norteamericanos. Sin embargo, el flujo de esta fibra textil se paralizó definitivamente en el último mes de 1917, tan pronto como los Estados Unidos comenzaron a

11 Índice de precios en Maluquer (2005, p. 1.288). Telegrama 208, de Riaño a Alvarado, 19/5/1917; tel. 193, de Alvarado a Riaño, 27/6/1917. Archivo General de la Administración (AGA), Asuntos Exteriores (AA.EE.), Caja 8.169. «The Special Position of Spain», The Washington Post, 11/7/1917. Desp. del Embajador inglés, 12/12/1917. NARA, RG 59, 1910-1929, 652.119/395. 
CUADRO 2

ENTRADAS/SALIDAS DE TONELAJE PROCEDENTE DE/CON DESTINO A ESPAÑA EN PUERTOS DE LOS ESTADOS UNIDOS

(Cifras en toneladas)

\begin{tabular}{|l|r|r|l|r|r|}
\hline Año 1917 & Entradas & Salidas & Año 1918 & Entradas & \multicolumn{1}{|c|}{ Salidas } \\
\hline Enero & 140.382 & 51.632 & Enero & 46.317 & 5.351 \\
Febrero & 95.887 & 32.209 & Febrero & 53.395 & 9.014 \\
Marzo & 82.508 & 26.731 & Marzo & 34.837 & 28.324 \\
Abril & 121.760 & 57.419 & Abril & 32.070 & 11.507 \\
Mayo & 102.559 & 57.288 & Mayo & 34.755 & 15.275 \\
Junio & 83.243 & 47.469 & Junio & 26.072 & 11.726 \\
Julio & 89.962 & 57.718 & Julio & 25.496 & 13.464 \\
Agosto & 75.427 & 40.280 & Agosto & 37.464 & 17.660 \\
Septiembre & 75.457 & 36.396 & Septiembre & 11.022 & 18.642 \\
Octubre & 76.949 & 39.600 & Octubre & 23.859 & 5.088 \\
Noviembre & 76.343 & 33.797 & Noviembre & 43.838 & 13.470 \\
Diciembre & 90.164 & 21.213 & Diciembre & 52.189 & 43.314 \\
\hline TOTAL & 1.110 .641 & 501.752 & TOTAL & 421.314 & 192.835 \\
\hline
\end{tabular}

Fuente: Monthly Summary of Foreign Commerce of the United States (ene. - dic. 1918).

disponerse para negociar con España un acuerdo tendente a agilizar el abastecimiento de la AEF. En este caso la medida tuvo un carácter mucho más drástico, ya que en el mes de enero de 1918 las aduanas estadounidenses no registraron ni una sola libra de algodón destinada a territorio español ${ }^{12}$.

Los preparativos estadounidenses para la negociación con España se prolongaron durante los meses de diciembre de 1917 y enero de 1918, desarrollándose a un doble nivel. De un lado, los oficiales a las órdenes de Washington dedicaron algún tiempo a precisar el detalle de lo que se deseaba obtener del gobierno español. Finalmente, el 20 de diciembre el Departamento de la Guerra emitió la siguiente lista: 300.000 mantas, 20.000 mulas, 10.000 .000 de pies de madera, 3.000 toneladas de judías, 4.000 de cebollas, 2.000 de arroz y 10.000 de carbón vegetal. Por otra parte, en función de los acuerdos adoptados por la Conferencia Interaliada, Norteamérica se vio obligada a coordinar sus esfuerzos con los del resto de naciones de la Entente interesadas en tratar con España. En este caso, el asunto incumbía principalmente a Francia, pues Inglaterra logró en diciembre la dilatada ratificación del Acuerdo Cortina, que parecía cubrir por el momento la mayor parte de las necesidades británicas. Por su parte, París

12 Tel. 797, de Willard a Lansing, 21/10/1917. FRUS, 1917, Suppl. 2, Vol. II, p. 1.208. Informe del Agregado Naval, 22/5/1918. NARA, RG 59, 1910-1929, 763.111Sp1/69. Carta de Lansing a Willard, 13/10/1917. FRUS, 1917, Suppl. 2, vol. II, p. 1.209. Tel. 418, de Riaño a Lema, 12/10/1917. AGA, AA.EE., Caja 8.155. Tel. 2.858, de Lansing a Willard, 26/10/1917. NARA, RG 59, 1910-1929, $652.119 / 256 \mathrm{~b}$. 
no sólo precisaba importar de España un número considerable de mercancías, sino que requería urgentemente préstamos con los que financiar su compra. En los últimos días de enero, y a iniciativa francesa, se constituyó el Bureau de Compras para España, que quedó bajo la dirección del Controlador General Eugène Mauclère, y contó con la presencia de un experto del Ministerio parisino de Finanzas, Charles Lasteyrie; ambos intervendrían directamente en las negociaciones con el ejecutivo español. Por su parte, los Estados Unidos comisionaron a Charles G. Dawes como su representante en el Bureau de Compras, pero hubieron de elegir a dos negociadores ex profeso para lidiar con los españoles. Dawes apuntó el nombre de August Belmont Jr., un acaudalado banquero de 65 años que se había presentado voluntario al servicio militar. Por su parte, el Embajador de los Estados Unidos en España, Joseph Edward Willard, orientó las miras de Washington hacia el fundador de la Hispanic Society de Nueva York, Archer Huntington. El banquero y el filántropo llegaron el 11 de enero a Madrid, donde contaron con la ayuda de un enviado del WTB, David Harrell ${ }^{13}$. Asimismo, iban equipados con instrucciones precisas:

«...el objetivo primario de estas negociaciones es facilitar las compras por cuenta del ejército americano [...]. Además, es muy deseable, desde nuestro punto de vista, que los gobiernos británico y francés obtengan importantes créditos en España, que alivien a este país la carga de mayores préstamos a aquellos Estados para que financien sus compras en España. Por ello, el Departamento de Estado cree que sus negociaciones, respaldadas por nuestro embargo, deberían llevarse a cabo cooperando estrechamente con sus colegas británicos y franceses» ${ }^{14}$.

Juntos, los delegados franceses y estadounidenses se reunieron el día 16 por primera vez con los representantes españoles encargados de ultimar los acuerdos: Pablo Garnica Echeverría, Subsecretario del Ministerio de Hacienda, y el Marqués de Urquijo, presidente del banco del mismo nombre y portavoz del consorcio financiero que, llegado el caso, debía proporcionar el dinero para los préstamos al gobierno galo. Las conversaciones de Belmont y Huntington con el tándem Garnica/Urquijo transcurrieron con inusitada rapidez, y el 30 de enero quedó ultimado un proyecto de acuerdo hispano-estadounidense. Según sus términos, la AEF obtendría permiso para comprar en España mantas, cebollas, pasas, arroz, jabón, lonas y aceite de oliva, a cambio de la concesión de licencias para importar de los

13 Carta a Lansing, 20/12/1917. NARA, RG 59, 1910-1929, 652.119/374. Tel. 531, de Alhucemas a Riaño, 3/12/1917. AGA, AA.EE., Caja 8.155. Nota de Lebrun a Klotz, 8/12/1917. Archives Diplomatiques - Ministère des Affaires Étrangères (AD-MAE). A.- Guerre, 1914-1918, vol. 1.446, pp. 22-28.

14 Tel. 852, de Lansing a Willard, 29/1/1918. NARA, RG 59, 1910-1929, 652.119/478b. 
Estados Unidos determinadas cantidades de petróleo y algodón. Ahora bien, cuando todo parecía indicar que España podía comenzar a respirar tranquila, se levantaron dos serios obstáculos para la ratificación del borrador por parte de Washington. En primer lugar, el Departamento de Estado no se encontraba en absoluto contento con el proceder de sus negociadores. El 2 de febrero, Lansing escribió a la Embajada en Madrid que «el acuerdo parece garantizar a España durante este año prácticamente todo lo que desee y pueda obtener de nosotros», dejando a los Estados Unidos «en una posición muy débil» ${ }^{15}$. En concreto, el Secretario de Estado deseaba incluir entre las contrapartidas del arreglo a una parte de la marina mercante española:

«El tonelaje total de España es de unas setecientas cincuenta mil a un millón de toneladas brutas. Proponemos, después de deducir el tonelaje requerido para las necesidades nacionales de España, estimado en trescientas mil toneladas, que los barcos restantes sean puestos a disposición de los Estados Unidos» ${ }^{16}$.

En segundo lugar, los Estados Unidos se apresuraron a clarificar que no sancionarían su convenio con España mientras las negociaciones hispanofrancesas no hubiesen culminado de forma satisfactoria para los aliados. A comienzos de febrero, las conversaciones entre Mauclère, Lasteyrie, Garnica y Urquijo se encontraban en un punto muerto, como consecuencia de las desavenencias surgidas en torno a la manera de avalar los créditos que el sindicato bancario español iba a conceder a los franceses. El gobierno de Madrid, «deseoso de repatriar sus rentas y las acciones de los principales negocios franceses o francoespañoles con mayoría francesa», había instruido a sus comisionados para que exigieran «valores españoles» como garantía de los préstamos. Lasteyrie, en estrecho contacto con intereses financieros de su país, se había negado a asumir tal petición y España sugirió como contrapropuesta que fueran los Estados Unidos los que respaldaran el empréstito. Washington, deseoso de restringir la salida de dólares hacia los países de la Entente y probablemente con dudas respecto a la solvencia de los franceses, se negó a suscribir la idea. Tras esto, el único resguardo que París parecía dispuesto a poner sobre la mesa eran sus propios bonos de guerra, que Urquijo y los financieros a quienes representaba rechazaban de plano. Ante la falta de entendimiento, el 7 de febrero

15 Tel. 986, de Willard a Lansing, 11/1/1918. NARA, RG 59, 1910-1929, 652.119/411. Tel. 999, de Willard a Lansing, 16/12/1918. FRUS, 1918, Suppl. 1, vol. II, p. 1.659. Tel. 13, de Thierry a Pichon, 11/1/1918. AD-MAE, A. Guerre, 1914-1918, vol. 1.446, p. 118. Tel. 1.023, de Willard a Lansing, 11/1/1918. FRUS, Ibidem, p. 1.660. Tel. 1.029, de Willard a Lansing, 30/1/1918. NARA, Ibidem, 652.119/488. Tel. 54, de Alhucemas a Riaño, 2/2/1918. AGA, AA.EE., Caja 8.185. Tel. 864, de Lansing a Willard, 2/2/1918. FRUS, ibid., p. 1.664.

16 Tel. 862, de Lansing a Willard, 2/2/1918. NARA, RG 59, 1910-1929, 652.119/541b. 
Lasteyrie dio por terminado el diálogo y anunció su intención de regresar a Francia ${ }^{17}$.

Por si todo esto fuera poco, Washington estaba mientras tanto contribuyendo a sacar de la circulación un número considerable de barcos hispanos: a comienzos de febrero había más de cuarenta retenidos en puertos estadounidenses, tras haberles negado el WTB tanto los permisos de salida como los de carboneo. Esta nueva obstrucción había comenzado a emplearse en diciembre de 1917, cuando el peso de los productos embarcados para España fue de tan sólo 21.213 toneladas, que descendieron a 5.351 el mes siguiente y al 9.014 en febrero (cuadro 2). Dada la aparente pasividad de los norteamericanos, el único camino que quedaba abierto a España para tratar de salir de la crisis consistía en la apelación a las necesidades francesas. Francia se encontraba en práctica bancarrota tras más de tres años de lucha y ansiaba un convenio casi tanto como el gobierno español. Desde este punto de vista, el ejecutivo parisino se postulaba como el perfecto candidato para lograr que los Estados Unidos suavizasen sus posturas, y fue el propio Alfonso XIII quien dio el paso definitivo. Poco después de la salida de Lasteyrie hacia París, el monarca se entrevistó con el Embajador de Francia en España, Joseph Thierry, manifestándole que conservaba «muy firme la voluntad de promover un acuerdo». Si éste se había visto coartado, era a consecuencia de «la imprevista demanda de un importante tonelaje español formulada por los Estados Unidos». Sin embargo, existía una vía de salida: si el gobierno de Washington abandonaba sus demandas relativas al tonelaje y daba salida a los barcos hispanos anclados en sus puertos, «él haría todo lo posible para asegurar la ratificación del acuerdo francoespañol y no tendría ninguna duda de su éxito». Los funcionarios franceses siguieron sin titubear el juego de España. El propio Lasteyrie apuntó a sus superiores que «está fuera de toda duda que las medidas adoptadas por los Estados Unidos son excesivas e inoportunas; han ido más allá de los objetivos y hecho mella en el sentimiento nacional de España». Asimismo, el Ministro de Marina escribió a Pichon que «no existe ninguna razón para no dar satisfacción al Rey». Finalmente, el Ministro de Finanzas Klotz expuso personalmente las exigencias españolas ante el representante del Departamento del Tesoro norteamericano en París, Oscar T. Crosby, recordándole que «nuestras negociaciones con España revisten tal interés para la causa común de los aliados que creo mi deber remitir los hechos a su atención y pedirle que intervenga si lo juzga oportuno» ${ }^{18}$.

17 Tel. 1.042, de Willard a Lansing, 4/2/1918. FRUS, 1918, Suppl. 1, vol. II, pp. 1.664-1.665 Desp. 21, de Thierry a Pichon, 22/1/1918; tel. 38, de Thierry a Pichon, 19/1/1918. AD-MAE, A. Guerre, 1914-1918, vol. 1.446, pp. 168-169 y 150. Tel. 59, de Alhucemas a Riaño, 7/2/1918. AGA, AA.EE., Caja 8.185. Tel. 1.052, de Willard a Lansing, 7/2/1918. FRUS, 1918, Suppl. 1, vol. II, p. 1.666 .

${ }_{18}$ Nota de Lasteyrie, 11/2/1918; tel. 108, de Thierry a Pichon, 8/2/1918. AD-MAE, A. Guerre, 1914-1918, vol. 1.447, pp. 55-58 y 43. Tel. 1.053, de Willard a Lansing, 7/2/1918. FRUS, 1918, 
En Washington, las conminaciones de Francia se unieron a las opiniones de Willard, quien en esos momentos también recomendaba «la liberación de las embarcaciones retenidas». El diplomático argumentaba que era imposible «tratar con España sin tener en cuenta su orgullo racial», y que ésta «no se someterá al racionamiento [... ni] aceptará ceder sus barcos». Al final, el Departamento de Estado decidió dejar la cuestión el tonelaje para negociaciones futuras. El 19 de febrero hizo saber que «no hay vapores españoles retenidos» y varios días después garantizó que «todos los barcos españoles que deseen hacerse a la mar pueden partir libremente, y les serán concedidos permisos de carboneo sin imponerles ninguna condición». Solventada la situación, las conversaciones hispano-francesas retomaron su curso, de nuevo con la presencia en Madrid de Lasteyrie. El 28 de febrero los negociadores establecieron una fórmula de compromiso, por medio de la cual los banqueros españoles aceptarían bonos de guerra franceses como contraprestación a un crédito de 350 millones de pesetas concedido al gobierno galo. Sin embargo, Francia accedía a completar la fianza «en la medida de lo posible», con los valores que España deseaba repatriar ${ }^{19}$.

Atados todos los flecos, el 7 de marzo se cerró por intercambio de notas un convenio hispano-galo que permitía a los franceses la compra de determinados productos en España. A la par, el ejecutivo de Madrid otorgó a Francia los permisos necesarios para obtener créditos con los que financiar sus adquisiciones en la Península Ibérica. En la misma fecha, y por idéntico procedimiento, Willard y Alhucemas pusieron en vigor el acuerdo comercial hispano-estadounidense. Con validez hasta el 31 de diciembre de 1918, el texto comprometía al gobierno español a conceder licencias de exportación para diversos artículos requeridos por la AEF: 300.000 mantas, 4.000 toneladas de cebollas, 2.000 toneladas de pasas, 2.000 toneladas de arroz, 20.000 sillas de montar, 240.000 yardas de lona, 20.000 libras de jabón de Castilla, 20.000 galones de aceite de oliva, 20.000 cueros para bridas, 20.000 cueros para atalaje y 100.000 libras de cueros. Asimismo, se permitía a Norteamérica la importación sin restricciones de lana, piritas, plomo, zinc, cobre y otros minerales. Por su parte, Washington confería a España licencias para exportar 35.000 balas de algodón y 4.000 toneladas de petróleo al mes; cobre y hierro en hojas, tubos o alambre; productos químicos; mate-

Suppl. 1, vol. 2, p. 1.667. Tel 1.073, de Willard a Lansing, 17/2/1918. NARA, RG 59, 1910-1929, 652.119/550. Tel. 67, de Estado a Riaño, 13/2/1918. AGA, AA.EE., Caja 8.185. Nota de Lasteyrie, 11/2/1918, nota del Ministro de Marina al Ministro de Asuntos Exteriores, 19/2/1918; tel. de Klotz a Crosby, reproducido en tel. del Ministerio de Finanzas a Thierry, 12/2/1918. AD-MAE, A. Guerre, 1914-1918, vol. 1.447, pp. 55-58, 94-95 y 62.

19 Tels. 1.047 y 1.058, de Willard a Lansing, 5 y 11/2/1918. FRUS, 1918, Suppl. 1, vol. II, pp. 1.666 y 1.667 . Tels. 896 y 915, de Lansing a Willard, 19 y 26/2/1918. FRUS, ibid., pp. 1.668 y 1.670. Vid., también, la correspondencia contenida en AGA, AA.EE., Caja 8.186. Tel. 6.772, de Polk a Willard, 5/3/1918. FRUS, ibid., p. 1.670. Acuerdo hispano-francés en AGA, AA.EE., Caja 8.185. Sobre los pormenores de este convenio $c f r$. Delaunay (1984). 
rial eléctrico y de telecomunicaciones; sulfato de amoniaco; aluminio y tabaco. No obstante, este otorgamiento quedaba sujeto a «las necesidades de los Estados Unidos y de sus aliados», y se efectuaría "sólo por la cantidad correspondiente a la satisfacción de las necesidades nacionales de España, evitando la formación de reservas ${ }^{20}$.

\section{EL ACUERDO FINANCIERO DE AGOSTO DE 1918}

El cierre del acuerdo relajó considerablemente algunas de las restricciones que más habían preocupado al ejecutivo español en las semanas anteriores. En marzo el WTB permitió la salida hacia la Península de 27.737 balas de algodón, y en abril hizo lo propio con 98.191 galones de productos petrolíferos (cuadro A-1). Por otra parte, en esos mismos meses se concedieron licencias de carboneo para barcos cuya capacidad de carga ascendía a 39.831 toneladas (cuadro 2). Sin embargo, estas cifras estaban muy por debajo de las medias de 1917, dejando al gobierno de los Estados Unidos con un amplio margen de maniobra para efectuar ulteriores concesiones a España en caso de desear el establecimiento de futuras negociaciones. Por otra parte, el artículo XIII del convenio de marzo reservó a los Estados Unidos un arma de presión muy importante, al estipular que «después de la firma del presente arreglo principiarán negociaciones para llegar a un acuerdo acerca del transporte por mar entre España y los Estados Unidos». Entretanto, se concedía un plazo de dos meses durante los cuales «cada uno de los dos Gobiernos facilitará en cuanto sea posible el carboneo de los barcos del otro que toquen en sus puertos, a fin de evitarles retrasos inútiles y de acelerar su rotación». Aunque el período inicial acabó prorrogándose indefinidamente en el mes de junio, quedó a discreción de Washington la posibilidad de derogar en cualquier momento el permiso para que los mercantes españoles se abasteciesen de combustible. En un principio, el gobierno estadounidense pretendió utilizar este activo para hacerse definitivamente con los servicios de una parte del tonelaje español dedicado al transporte de mercancías. Sin embargo, el Departamento de Estado acabó desechando definitivamente la idea a finales de julio, una vez quedó convencido de que resultaba imposible obtener de España ningún compromiso en firme. Para entonces las preocupaciones de Washington se encontraban aferradas a otro problema: la creciente devaluación del dólar frente a la peseta ${ }^{21}$.

La depreciación de la divisa estadounidense se había acelerado desde el año 1916 —de una media anual de 5,23 pesetas/dólar pasó en 1917 a 4,43 y

20 La versión española del acuerdo en Archivo del Ministerio de Asuntos Exteriores (AMAE), H 2443. La inglesa en FRUS, 1918, Suppl. 1, vol. II, pp. 1.671-1.674.

21 Tel. 1.101, de Lansing a Willard, 8/5/1918; tel. 1.278, de Lansing a Willard, 29/6/1918; tel. 1.608, de Willard a Lansing, 31/7/1918. FRUS, 1918, Suppl. 1, vol. II, pp. 1681, 1686 y 1.691-1.692. 
en 1918 a 4,17-, a pesar de que la balanza comercial hispano-norteamericana se inclinaba favorablemente del lado de los Estados Unidos. A juicio de Arthur Young, este fenómeno era consecuencia directa de la existencia de un tipo de cambio fijo entre el dólar, la libra esterlina y el franco francés, mantenido artificialmente por los gobiernos de Londres y París. La situación se presentaba particularmente atrayente para los bancos españoles situados en ambas capitales, que recibían un volumen considerable de letras de cambio en moneda local, como consecuencia de las cuantiosas ventas de productos peninsulares a Francia e Inglaterra. En lugar de transformar esas letras directamente en pesetas, resultaba mucho más provechoso hacerlas pasar por Nueva York para convertirlas en dólares, cuya cotización respecto a la peseta era relativamente alta. De esta manera se creó en la ciudad de la gran manzana una demanda excepcional de divisas españolas, que hizo crecer su valor respecto al dólar. No obstante, la depreciación de la moneda americana se mantuvo en términos razonables mientras fue posible transformar en oro libras y francos dentro de los Estados Unidos. En los seis primeros meses de 1917, el 26,7 por cien del oro que salió de los Estados Unidos tuvo como destino España, una circunstancia que no pasó desapercibida a los reporteros del New York Times. Sin embargo, ya vimos que en agosto de 1917 Washington levantó un embargo sobre la salida de metales preciosos, que hizo caer radicalmente la cotización desde las 4,50 pesetas por dólar de ese mes, a las 3,72 de julio de 1918 (cuadro 3) ${ }^{22}$.

Charles G. Dawes y algunos de los participantes norteamericanos en la Conferencia Interaliada de noviembre-diciembre de 1917 habían propuesto subsanar el problema mediante la obtención en España de préstamos con los que financiar las compras de la AEF. Sin embargo, no fue hasta febreromarzo de 1918 cuando el Secretario del Tesoro, William G. McAdoo y su subalterno Russel C. Leffingwell, con la posible ayuda del National City Bank, concibieron un primer plan para detener la caída de la moneda estadounidense: un consorcio de banqueros norteamericanos depositaría, en una cuenta abierta a nombre del gobierno español en la Reserva Federal de Nueva York, determinadas cantidades en dólares, cuyo contravalor en pesetas sería puesto por España a disposición de los diversos agentes de compras estadounidenses trabajando al sur de los Pirineos. El ejecutivo español dejaría intacto el saldo de dicha cuenta hasta seis meses después de ratificado el tratado de paz, momento en que se le permitiría repatriar a territorio peninsular su equivalente en oro ${ }^{23}$.

Ante la momentánea imposibilidad de enviar un agente oficial del Tesoro para estudiar la viabilidad del proyecto, McAdoo y Gibbs recu-

22 Martín Aceña y Pons (2005, pp. 705-706). «Spain to Get 1,100,000 in Gold»; «More Gold for Spain», The New York Times, 17/5/1917 y 7/6/1917. Young (1920, pp. 96-98).

${ }_{23}$ Carta de Leffingwell a Lansing, 2/2/1918, y carta de McAdoo a Lansing, 11/3/1918. NARA, RG 59, 1910-1929, 652.119/495 y 640. Cfr., también, Diario de Chandler P. Anderson, 13/2/1918. Library of Congress (LOC), Chandler P. Anderson Papers, Container I. 
DIPLOMACIA ECONÓMICA Y BALANZA DE PAGOS. LOS PACTOS HISPANO...

CUADRO 3

EXPORTACIONES DE ORO ESTADOUNIDENSE A ESPAÑA Y RELACIÓN DÓLAR/PESETA (1917-1918)

\begin{tabular}{|l|r|r|c|l|c|c|c|}
\hline Año 1917 & Miles \$ & $\%^{(*)}$ & CAMBIO & Año 1918 & Miles \$ & $\%^{(*)}$ & CAMBIO \\
\hline Enero & 4.444 & 21,5 & 4,70 & Enero & 0 & 0,0 & 4,12 \\
Febrero & 3.617 & 16,4 & 4,75 & Febrero & 0 & 0,0 & 4,01 \\
Marzo & 4.267 & 23,8 & 4,66 & Marzo & 0 & 0,0 & 3,81 \\
Abril & 4.400 & 25,9 & 4,63 & Abril & 0 & 0,0 & 3,59 \\
Mayo & 21.011 & 36,4 & - & Mayo & 0 & 0,0 & 3,60 \\
Junio & 15.983 & 23,8 & 4,23 & Junio & 0 & 0,0 & 3,66 \\
Julio & 20.328 & 29,4 & 4,36 & Julio & 10 & 0,1 & 4,00 \\
Agosto & 14.816 & 32,2 & 4,44 & Agosto & 0 & 0,0 & 4,34 \\
Septiembre & 10.471 & 33,4 & 4,46 & Septiembre & 0 & 0,0 & 4,62 \\
Octubre & 2.729 & 24,5 & 4,30 & Octubre & 0 & 0,0 & 4,99 \\
Noviembre & 0 & 0,0 & 4,24 & Noviembre & 0 & 0,0 & 4,98 \\
Diciembre & 0 & 0,0 & 4,16 & Diciembre & 0 & 0,0 & 4,97 \\
\hline
\end{tabular}

Fuentes: Monthly Summary of Foreign Commerce of the United States; Young (1920).

Notas:

${ }^{(*)}$ Sobre el total de las exportaciones estadounidenses de oro.

rrieron a la figura de Otto Hermann Kahn, un importante banquero de origen alemán, socio de la casa de inversión neoyorquina Kuhn, Loeb \& Co., cuya importancia era sólo superada por J. P. Morgan. Kahn tenía previsto por entonces un viaje a España, Francia e Inglaterra, para sondear diversas posibilidades de inversión en nombre de la American International Corporation, una firma fundada en 1916 bajo los auspicios del Citybank, y dedicada a la gestión de transacciones en el extranjero. A su misión original se añadió el encargo de desarrollar «una investigación, no oficial, de la situación financiera de España en relación con los Estados Unidos». Kahn arribó el 11 de junio a Madrid, donde se entrevistó personalmente con el Ministro de Fomento, Francesc Cambó, con Maura y con el propio Alfonso XIII ${ }^{24}$. Tras acabar su misión, ofreció al gobierno norteamericano las bases de un proyecto mejorado para la obtención de fondos en España:

«...no habría ninguna dificultad en conseguir un crédito de 500.000.000 de pesetas en España, en letras a tres meses susceptibles de renovación por un año o más, [efectuado] por un sindicato bancario español, a un sindicato bancario americano [...]. El crédito ten-

${ }^{24}$ Sobre Kahn $c f r$. Collins (2002) y «Death at n. ${ }^{\circ}$ 52», Time Magazine, 9/IV/1939. Sobre su relación con la AIT, «\$500.000.000 Gain in Venture in World Trade», The New York Times, 24/11/1914. Sobre las entrevistas de Kahn, LOC, Willard Papers, I, 114, 5. Y «Spain's King Receives Kahn», The New York Times, 20/6/1918. 
dría que asegurarse con un aval bancario y las letras se descontarían en el Banco de España» ${ }^{25}$.

De manera más o menos consciente, los esfuerzos de Kahn en Madrid tejieron la urdimbre sobre la que acabarían asentándose las negociaciones financieras hispano-norteamericanas. Durante el mes de junio, antes incluso de que el banquero hubiese finalizado sus pesquisas, y con el clima bilateral algo más calmado, el Departamento del Tesoro designó legalmente a uno de sus funcionarios para acordar los préstamos con España. Se trataba de Norman Hezequiah Davis, un hombre de negocios relacionado con Cuba, al que esperaba un brillante futuro en la política internacional de su país. Tres eran los puntos principales que debían guiar la acción de Davis: en primer lugar, trataría de conseguir del gobierno español el pago en pesetas, a un tipo fijo, de las mercancías que los importadores hispanos compraban a los Estados Unidos. En segundo lugar, concretaría los mecanismos bajo los cuales los comerciantes y agentes de compras estadounidenses podrían obtener préstamos en España. Y por último, requeriría de Madrid el permiso para que un número indeterminado de trabajadores españoles pudieran desplazarse a Francia al objeto de efectuar «trabajos no beligerantes» en beneficio de los aliados ${ }^{26}$.

Antes de partir hacia Europa, Davis preparó concienzudamente el terreno, reuniéndose con representantes del National Bank of Commerce, el National City Bank, la Guaranty Trust Company, el Mercantile Bank of the Americas y la Equitable Trust Company, al objeto de recabar ideas para la conclusión de un arreglo con España lo más perfecto posible. Asimismo, visitó a Juan Riaño, del que obtuvo cartas personales de recomendación dirigidas al entonces Ministro de Estado, Eduardo Dato y al Comisario de Abastecimientos, Juan Ventosa. Ya en el Viejo Continente, se encontró con Otto Kahn y tuvo varias conversaciones con delegados de las haciendas francesa y británica, buscando conocer su opinión personal acerca de la situación financiera en territorio español. Con toda esta información en la mano, Davis diseño un plan de acción basado en un abandono de las tácticas coactivas. Así, en sus comunicaciones a Washington escribió que «el bloqueo comercial a España es innecesario y desaconsejable», y que «retener los barcos no es conveniente». Antes bien, «podemos lograr más a través de una política generosa y sincera, explicando que deseamos proveerlos tanto como sea posible, incluso haciendo algún sacrificio, pero que no podemos permitírnoslo a no ser que ellos, de la misma manera, nos ayuden a suplir nuestras necesidades aquí». Esta opción a favor de la benevolencia

25 Tel. 54, de Laughlin a Lansing, 2/7/1918. NARA, RG 59, 1910-1929, 852.51/52.

26 Sobre Davis cfr. Whiteman (1958), Dallek (1975) y «Debts, Disarmament \& Davis», Time Magazine, 12/12/1932. Su mission en tel. 1.415, de Lansing a Willard, 12/8/1918. FRUS, 1918, Suppl. 1, vol. 2, pp. 1.696-1.697. La expresion sobre los trabajadores aparece en el proyecto de acuerdo que Davis presentó a Dato. AMAE, H 2443. 
puede servir para explicar el inusitado aumento en el mes de agosto de las ventas a España de productos como el algodón, que ascendieron a 38.905 balas, frente a las 8.841 del mes anterior (cuadro A-1) ${ }^{27}$.

Forjadas estas premisas, el agente financiero procedió a entablar negociaciones con el gobierno español, y el 11 de agosto tuvo una entrevista con Maura, a la sazón Presidente del Consejo, así como con otros miembros del gabinete. En estos y otros encuentros ulteriores, Davis sacó a colación los tres ejes en los que se centraban sus instrucciones. De ellos, el que más polémica suscitó fue la pretensión norteamericana de establecer un tipo de cambio fijo entre el dólar y la peseta ${ }^{28}$. Finalmente se llegó a una fórmula de compromiso que además salvaguardaba los intereses de España más allá de la expiración del convenio comercial firmado en marzo:

«La liquidación de estas compras hasta el 31 de diciembre próximo se efectuarán (sic) en pesetas o dollars al tipo de cambio corriente en la fecha de efectuarse el pago. Después del 31 de diciembre quedará sujeta a las reglas que adopten los EEUU en carácter general para los países neutrales en que concurran las mismas circunstancias que en España» ${ }^{29}$.

Las negociaciones para la obtención de los créditos fueron más largas pero menos complicadas. Su mayor duración se debió a las múltiples instancias que debían intervenir en las operaciones de préstamo. En primer lugar, para que uno o varios banqueros españoles pudiesen conceder empréstitos a representantes oficiales de un país extranjero, se requería la autorización previa del gobierno español. Antes de otorgarla, Dato y Ventosa solicitaron de los Estados Unidos «seguridades de que [...continuarían] abasteciendo [...a España] con algodón, combustibles, etc. ». Davis contestó que, en ese caso, el ejecutivo de Maura debería permitir la venta al ejército norteamericano de mulas y caballos, no incluidas en el acuerdo de marzo y sujetas a embargo por parte de España ${ }^{30}$. Nuevamente se optó por una vía intermedia, que no mencionaba artículos ni cantidades, pero ponía de manifiesto la voluntad de mantener vivo el tráfico bilateral:

«Además del intercambio de mercancías establecido en el acuerdo de 7 de marzo de 1918, ambos gobiernos [...] permitirán la exportación

\footnotetext{
27 «Seeks to Stabilize Spanish Exchange», The New York Times, 6/7/1918. Tel. 477, de Riaño a Dato, 3/7/1918. AGA, Asuntos Exteriores, Caja 8.185. Tel. 1.451, ya cit. Tel. 1.632, de Willard a Lansing, 3/8/1918. FRUS, 1918, Suppl. 1, vol. II, p. 163.

28 Tel. de Willard a Lansing, 11/8/1918. FRUS, ibid., pp. 1.697-1.699.

29 Texto del acuerdo del 29 de agosto. AMAE, H 2443

30 Tel. de Willard a Lansing, 16/8/1918. FRUS, 1918, Suppl. 1, vol. II, pp. 1.700-1.702. Tel. 4.549, de Sharp a Lansing, 23/7/1918. NARA, RG 59, 1910-1929, 652.119/1201. Proyecto de acuerdo de Davis, 16/8/1918. AMAE, H 2443.
} 
de cantidades adicionales de los artículos que en dicho acuerdo se mencionan y de otros productos que puntualmente se solicitan dentro de las posibilidades de cada país, teniendo en cuenta las necesidades de su abastecimiento interior y sus compromisos internacionales» ${ }^{31}$.

El segundo paso consistía en ultimar los detalles concretos del crédito con los banqueros españoles interesados en suscribirlo. Para esta tarea, los interlocutores del delegado estadounidense fueron el Banco Urquijo y el Banco de Barcelona, representados por el vicepresidente del primero, Luis de Urquijo, y el director gerente del segundo, José María Martínez Marqués. Ambos concertaron con Davis la emisión de un préstamo por valor de doscientos cincuenta millones de pesetas, que un sindicato bancario español pondría a nombre de un consorcio similar de entidades financieras de los Estados Unidos. De la cantidad total, los dos bancos negociadores adelantarían una suma inicial de setenta y cinco millones. El resto sería desembolsado por el banco o bancos que el gobierno español designase, antes del 25 de septiembre. Los créditos se formalizarían a través de letras de cambio a tres meses, que las casas de banca estadounidenses avalarían mediante el depósito en Nueva York de su equivalente en obligaciones del gobierno de los Estados Unidos. Dichas letras se descontarían con las pesetas obtenidas por los norteamericanos mediante las ventas a España de algodón, petróleo y otros productos ${ }^{32}$.

Respecto al tercero de los asuntos incluidos en la agenda de Norman Davis, el gobierno de Maura dio su visto bueno oficioso a la contratación, por parte de los aliados, de trabajadores españoles. Éstos podrían ser llevados a Francia «siempre que pudiera hacerse sin infringir la neutralidad española». Con todos los polos de la negociación cerrados, el 29 de agosto pudieron concluirse formalmente dos acuerdos hispano-norteamericanos. El primero se efectuó por intercambio de notas entre Dato y Davis, y se definió como «complementario del celebrado [...] el 7 de marzo de 1918». Sus cláusulas recogían la autorización gubernamental para «la concesión por banqueros españoles a banqueros de los Estados Unidos de América de créditos hasta la cantidad de doscientos cincuentas millones de pesetas». El segundo compromiso fue signado por el representante norteamericano, Urquijo y Martínez Marqués, y detallaba los pormenores del empréstito descrito anteriormente ${ }^{33}$.

La ejecución del sistema de préstamos apenas tropezó con ningún obstáculo. Los Estados Unidos eligieron al Mercantile Bank of the Americas, única casa de banca norteamericana con sucursal en España - concreta-

\footnotetext{
31 Acuerdo del 29 de agosto, ya citado.

32 Términos del acuerdo financiero del 29 de agosto. AMAE, H2443.

33 Tel. de Willard a Lansing, 16/8/1918, ya citado. Observaciones de Ventosa al proyecto de Davis, 19/8/1918. AMAE, H 2443. Versiones inglesas de los acuerdos en FRUS, 1918, Suppl. 1, vol. II, pp. 1.708-1.711.
} 
mente en Barcelona-, para ser depositaria de las letras de cambio que se giraran con cargo al crédito. El Mercantile quedó igualmente facultado para formar el consorcio bancario estadounidense que debía avalar los doscientos cincuenta millones de pesetas convenidos y que fue constituido a mediados de noviembre. En la operación participaron los principales bancos de Nueva York - caso del National City Bank o el Chase National Bank- así como de otras grandes ciudades del este y el centro de los Estados Unidos -el First National Bank de Boston, el National Bank of the Republic de Chicago,...-. Asimismo, entre los meses de septiembre, octubre y noviembre de 1918, los Bancos Urquijo y de Barcelona pusieron a disposición del gobierno de los Estados Unidos los 75.000.000 de pesetas que se habían comprometido a otorgar en concepto de adelanto. Estas dos corporaciones dirigieron a su vez la formación del correspondiente sindicato financiero que debía proporcionar los 175 millones restantes. Sin embargo, para cuando se completó su constitución, el armisticio se había convertido en un hecho y la guerra había tocado a su fin. Con ello, las autoridades norteamericanas no se vieron en la necesidad de disponer de la totalidad de su línea de crédito, limitándose a retirar tan sólo 50 millones en enero de 1919 y otros 30 al mes siguiente. Estas sumas fueron devueltas de manera progresiva mediante el descuento de las correspondientes letras de cambio, que comenzó en otoño de 1919 y continuó a lo largo del año siguiente ${ }^{34}$.

\section{LOS EFECTOS DE LA DIPLOMACIA ECONÓMICA HISPANO-ESTADOUNIDENSE EN LA BALANZA DE PAGOS}

En los primeros compases de este trabajo asentamos nuestra intención de resaltar las conexiones existentes entre la evolución de la balanza de pagos española y el devenir de la diplomacia económica hispano-norteamericana a lo largo del período 1917-1918. Esta relación tuvo su materialización más clara en el caso de los intercambios comerciales. Estudiando las cifras ofrecidas por Sudrià (cuadro 1), se pone de manifiesto que los Estados Unidos fueron los máximos responsables del declive experimentado en las importaciones españolas durante 1918. Éstas sumaron un total de 776,5 millones de pesetas, que representaban un decremento de 187 millones respecto del año anterior. Al contemplar caso por caso las importacio-

${ }^{34}$ Carta del Segundo Secretario de la Embajada de los Estados Unidos en España a Norman H. Davis, 20/1/1919. LOC, Willard Papers, I, 116, 4. Una lista completa de los bancos en la carta de la División de Cambios del Mercantile a Juan Riaño, 21/11/1918. AMAE, H 2443. Tel. 2.417, de Willard a Lansing, 17/2/1919; carta del Banco Urquijo a las entidades participantes en el crédito, enero de 1919; tel. 2.048, de Polk a Willard, 13/4/1919. NARA, RG 84, Embassy Madrid, 1919. Para el descuento de las letras de cambio ver Class 851.6 en NARA, RG 84, Embassy Madrid, 1919 y 1920. Young (1920, pp. 87-90). 
nes provenientes de los principales socios mercantiles de España, se descubre asimismo que la caída con respecto a Gran Bretaña fue de 22,5 millones de pesetas, con respecto a Francia de 26,8 millones y con respecto a los Estados Unidos de 194,2 millones. Las pérdidas relativas a estos países suman un total de 243,5 millones, a los que es necesario contraponer el aumento de 55,5 millones en las compras a Argentina. Una cifra que compensa grosso modo las reducciones con respecto al eje franco-británico y deja a la República Norteamericana como la causante principal de la merma total.

Por otra parte, todo parece indicar que esa recesión en 1918 de las importaciones españolas desde los Estados Unidos fue consecuencia directa de la política de embargos aplicada por Washington. Aunque la mayor parte de las medidas restrictivas levantadas por Norteamérica fueron arbitradas en la segunda mitad de 1917, el valor de las ventas norteamericanas a la Península no sólo no disminuyó en ese año, sino que creció considerablemente desde los 399,2 millones de dólares de 1916 a los 516,7 millones de 1917. Para explicar este fenómeno es necesario fijarse en dos factores: el momento en que las prohibiciones se aplicaron de manera efectiva contra España y el peso especial del algodón. Al objeto de concretar estos puntos hemos procedido a efectuar una reconstrucción mensual de las exportaciones estadounidenses a España, para la que nos hemos basado en el Monthly Summary of Foreign Commerce of the United States, emitido regularmente por el Bureau of Foreign and Domestic Commerce del Departamento de Comercio. Una publicación que no listaba exhaustivamente todos los artículos destinados a territorio español, pero de la que hemos extraído una selección lo suficientemente amplia como para cubrir el 57,6 y el 64,6 por cien de los mismos durante los años 1917 y 1918 (cuadro A-1).

Como ya mencionamos anteriormente, las adquisiciones españolas de productos estadounidenses crecieron progresivamente a partir de 1914. Este patrón permaneció aparentemente imperturbable durante el primer semestre de 1917, cuando apenas se habían dejado sentir los efectos de la beligerancia norteamericana. Es cierto que en esos meses se registraron algunas oscilaciones mensuales, como consecuencia seguramente de las incertidumbres derivadas del resurgimiento de la campaña submarina alemana. Algo que parece confirmarse por el pronunciado descenso del tonelaje en camino desde Norteamérica hacia la Península, que en febrero y marzo fue respectivamente de tan sólo 32.209 y 26.731 toneladas, frente a las 51.632 toneladas del mes de enero (cuadro 2). No obstante, entre los últimos seis meses de 1916 y los primeros de 1917, las exportaciones estadounidenses a territorio español subieron de 33.403.916 dólares a 43.574.434 dólares. Una diferencia de 10.170.518 dólares, que da cuenta de un 37,3 por cien del crecimiento total de dichas exportaciones entre 1916 y 1917, y que puede achacarse tanto a la mayor cantidad de productos 
importados como al aumento de precio experimentado por algunos de ellos. En el primer caso se situaría el azúcar, del que entre julio y diciembre de 1916 se despacharon a España 14.933.532 libras, que crecieron hasta 50.058.414 libras entre enero y junio del año siguiente. En el segundo grupo se encontraría el algodón, del que en el mismo período se intercambiaron 5.874.200 libras menos, pero donde el valor de la transacción ascendió 521.721 dólares.

La dinámica varió significativamente en el segundo semestre de 1917, cuando aconteció la mayor parte del aumento interanual de las exportaciones a España: un 42,7 por cien. En los meses del verano las cifras de comercio mensual siguieron mostrando bastantes altibajos, seguramente a raíz de los desajustes administrativos propios de la conversión norteamericana a la beligerancia. Sin embargo, la situación pareció estabilizarse a partir de agosto, coincidiendo con la creación del Exports Administrative Board. Desde ese momento, las restricciones arbitradas por Washington comenzaron a mostrar sus primeros efectos: las exportaciones de azúcar y petróleo, que en agosto sumaron 4.584.024 libras y 1.007.018 galones respectivamente, habían desaparecido completamente a finales de año. Sin embargo, estas limitaciones apenas tuvieron algún efecto en la valoración total de comercio, debido a la preservación del movimiento de algodón hacia España, al que tanto el Exports Board como posteriormente el WTB continuaron dando vía libre hasta diciembre. El precio de esta fibra textil, que entre julio y diciembre copó el 49,6 por cien de las exportaciones norteamericanas hacia la Península, siguió aumentando de manera significativa. Así, si bien las cantidades de algodón adquiridas por España fueron similares en los dos semestres de 1917 -95.503.419 libras durante el primero y 96.665.247 en el segundo-, su precio subió un total de 8.616.256 dólares — de 18.515 .710 a 26.610 .694 dólares-. Un ascenso que sirve para explicar el 56 por cien del crecimiento de esas exportaciones entre los últimos seis meses de 1916 y el segundo semestre del año siguiente, y que no sólo compensó las caídas ocasionadas por la aplicación de los primeros embargos, sino que contribuyó a acrecentar significativamente el precio total de los intercambios. La otra porción de ese incremento residió principalmente en los productos no listados en el cuadro A-1, que siguieron circulando con relativa libertad y pudieron verse sometidos a fenómenos inflacionarios similares.

Son precisamente las reducciones en el envío de algodón y productos secundarios las que dilucidan la significativa rebaja en las importaciones españolas del año 1918. Como vimos, el gobierno español se mostró preocupado desde fecha temprana por la eventualidad de un cierre total de las exportaciones norteamericanas. Cuando los temores se tornaron en hechos, las autoridades del país se pusieron a negociar para salvaguardar al menos la fluidez de dos productos básicos: el algodón, que mantenía funcionando la industria textil catalana, y el petróleo, que servía principalmente como 
iluminante y lubricante. España jugó entonces con las penurias financieras de los franceses y las necesidades de abasto del ejército estadounidense para lograr el acuerdo firmado el 7 de marzo de 1918. Sin embargo, lo que los españoles recibieron estuvo en ocasiones lejos de lo prometido en el convenio, como pone de manifiesto el caso de la materia prima textil. Entre marzo y noviembre, mes en que acabó la guerra, los Estados Unidos vendieron a España una media de 16.818 balas de algodón ( 1 bala $\cong 550$ libras), alrededor de la mitad de las 35.000 que se habían concertado. En realidad, las considerables oscilaciones existentes en las importaciones hispanas de algodón y otras mercaderías como las parafinas apuntan a que Washington siguió utilizando su comercio con España para influir la acción de los gabinetes de Madrid. Ya vimos cómo en agosto el deseo de afrontar la negociación del pacto financiero exhibiendo muestras de buena voluntad coincidió con un cierto auge en el tráfico hispano-estadounidense. Algo muy distinto de lo que ocurrió en octubre, cuando Norteamérica buscó forzar al gobierno de Madrid para autorizar la venta de un número considerable de mulas destinadas al ejército de Pershing. Aunque en este caso la documentación diplomática es poco clara, las estadísticas hacen coincidir el hecho con una nueva oleada de coerción contra España, dada la ausencia total en ese mes de exportaciones de algodón y la reducción en las cifras tonelaje entre los Estados Unidos y la Península: tan sólo 5.088 toneladas ${ }^{35}$.

En su totalidad, entre 1917 y 1918 las adquisiciones hispanas de algodón estadounidense se redujeron en 4,24 millones de dólares, y fueron responsables del 16 por cien del descenso total de las importaciones españolas desde Norteamérica. Por otra parte, las transacciones de productos secundarios fueron las culpables de un 63 por cien de esa rebaja, con una caída de 14,67 millones de dólares. Este último fenómeno se asocia directamente con la escasez de tonelaje, fruto a su vez tanto de la política restrictiva del WTB en relación con el carboneo de barcos, como de la campaña submarina de las Potencias Centrales. De hecho, si en 1917 la media mensual de tonelaje entre Norteamérica y España fue de 41.813 toneladas, en 1918 se redujo hasta 16.070 toneladas. Una coyuntura que obligó en agosto al gobierno de Maura a autorizar la requisa de todos los barcos españoles anclados en Norteamérica, para asegurarse de que llenaban sus bodegas con mercancías de primera necesidad ${ }^{36}$.

A la hora de reforzar la conexión entre los contactos diplomáticos hispano-estadounidenses y la evolución de las relaciones mercantiles, puede resultar útil una comparación de la situación de España con la del resto de

35 Pershing (1995, vol. 2, pp. 130-131 y 169-170). Tels. 4.549, 5.589, 5.604 y 5.695, de Sharp a Lansing, 23/7/1918 27/10/1918, 28/10/1918 y 3/11/1918. Tel 1.886, de Willard a Lansing, 3/10/1918. Tel. 1.858, de Lansing a Willard, 29/11/1918. NARA, RG 59, 1910-1929, 652.119/1201, 2000, 2015, 2246, 1886 y 2246. Tel. 5.498, de Sharp a Lansing, 20/10/1918. FRUS, 1918, Suppl. 1 , vol. II, p. 1.712 .

36 Tel. 417, de Dato a Riaño, 22/8/1918. AGA, Asuntos Exteriores, Caja 8.186. 
neutrales europeos. Dinamarca, Holanda, Noruega, Suecia y Suiza se vieron sometidos, tras el estallido de la guerra, a problemas de abastecimiento similares a los que afrontó la Península Ibérica. Sin embargo, existía un elemento que los colocaba en una posición fundamentalmente diferente a la de España: la geografía. Situados en el extremo occidental de Europa, los españoles se encontraban relativamente a salvo del bloqueo británico, y pudieron desplegar sin excesivas trabas el comercio trasatlántico. En cambio, se vieron forzados a desistir de cualquier trueque significativo con Alemania. Por su parte, el resto de neutrales del Viejo Continente compartía fronteras con las Potencias Centrales, en tanto que su acceso al Atlántico se vio obstaculizado tanto por la acción restrictiva de los británicos como por las patrullas de los sumergibles germanos. Así pues, mientras entre 1915 y 1916 el movimiento de bienes entre los Estados Unidos en España creció 14.485.755 dólares, el tráfico desde Norteamérica a Dinamarca descendió 17.177.509 dólares, a Holanda 129.242.924 dólares, y a Suecia 37.263.953 (cuadro 4). Dos excepciones a esta tendencia fueron las de Suiza y Noruega, fruto seguramente en el caso de la primera de su calidad de nación a caballo entre Francia y Alemania.

Las diferencias entre España y los países no beligerantes del norte de Europa se dejaron sentir plenamente en el momento de la ejecución de la política norteamericana de embargos. Todos los neutrales comenzaron a ser víctimas de la mano dura de los norteamericanos a lo largo del otoño de 1917, pero en el caso español las presiones respondían a un objetivo primario diferente. Washington deseaba de España que se convirtiera en proveedora de las tropas estadounidenses, en tanto que el propósito de su dialéctica con el resto de los neutrales pasaba por evitar que siguieran exportando más mercaderías a los alemanes. Tal circunstancia revistió las relaciones de estos últimos con los Estados Unidos de una especial tensión, que se manifestó en la conclusión de acuerdos bastante tardíos. Si España pudo firmar el suyo el 7 de marzo, Dinamarca no hizo lo propio hasta el 18 de septiembre, Holanda hasta el 17 de diciembre —aunque llegó a un modus vivendi el 25 de enero-, Suecia hasta el 29 de mayo - con otro modus vivendi el 29 de enero- y Noruega hasta el 30 de abril. Sólo Suiza se salió una vez más de esta tendencia, con un convenio cerrado el 25 de diciembre de 1917. Igualmente, si en España la firma del pacto no acabó con las oscilaciones en sus compras a Norteamérica, en el caso de los otros neutrales estas alteraciones fueron de un talante más severo. Únicamente Noruega y Dinamarca aumentaron significativamente sus importaciones inmediatamente después de cerrar sus negociaciones, en abril y septiembre respectivamente. En cambio, los modus vivendi de Suecia y Holanda no impidieron que en el mes de febrero ninguna de las dos recibiera una sola caja de artículos estadounidenses (cuadro 4) ${ }^{37}$.

\footnotetext{
37 Bailey (1966).
} 


\section{CUADRO 4}

COMERCIO DE LOS ESTADOS UNIDOS

CON LOS NEUTRALES EUROPEOS (1913-1914)

(Cifras en miles de dólares)

\begin{tabular}{|c|c|c|c|c|c|c|c|c|c|c|c|c|}
\hline & \multicolumn{2}{|c|}{ ESPAÑA } & \multicolumn{2}{|c|}{ DINAMARCA } & \multicolumn{2}{|c|}{ HOLANDA } & \multicolumn{2}{|c|}{ NORUEGA } & \multicolumn{2}{|c|}{ SUECIA } & \multicolumn{2}{|c|}{ SUIZA } \\
\hline & Imps & Exps & Imps & Exps & Imps & Exps & Imps & Exps & Imps & Exps & Imps & Exps \\
\hline 1913 & 24.412 & 30.773 & 2.467 & 18.617 & 37.639 & 121.552 & 8.412 & 9.256 & 11.875 & 13.387 & 24.362 & 836 \\
\hline 1914 & 22.041 & 27.816 & 3.845 & 41.945 & 37.500 & 100.744 & 11.977 & 19.635 & 11.715 & 30.961 & 21.513 & 770 \\
\hline 1915 & 18.092 & 45.697 & 2.744 & 73.507 & 28.494 & 142.973 & 6.982 & 46.281 & 11.373 & 85.232 & 19.900 & 5.994 \\
\hline 1916 & 32.578 & 64.316 & 3.040 & 56.329 & 43.602 & 13.730 & 6.430 & 66.210 & 18.857 & 47.968 & 22.414 & 13.654 \\
\hline 1917 & & & & & & & & & & & & \\
\hline Ene & 3.340 & 9.131 & 59 & 5.476 & 4.079 & 14.777 & 380 & 7.934 & 2.404 & 5.674 & 1.350 & 2.212 \\
\hline Feb & 3.070 & 6.007 & 115 & 3.010 & 2.113 & 5 & 405 & 5.983 & 2.039 & 2.397 & 1.440 & 2.816 \\
\hline Mar & 2.735 & 6.983 & 45 & 4.736 & 64 & 1.146 & 795 & 7.586 & 1.182 & 2.895 & 1.331 & 2.021 \\
\hline Abr & 4.692 & 7.934 & 7 & 3.724 & 110 & 13.955 & 158 & 6.903 & 610 & 1.269 & 1.317 & 2.155 \\
\hline May & 2.924 & 8.415 & 154 & 2.578 & 2.303 & 9.670 & 1.708 & 9.062 & 2.305 & 1.038 & 1.129 & 2.353 \\
\hline Jun & 3.955 & 5.28 & 415 & 8.782 & 2.852 & 2.608 & 5.344 & 9.385 & 2.093 & 4.016 & 2.486 & 1.800 \\
\hline Jul & 3.030 & 6.198 & 82 & 1.543 & 3.060 & 5.417 & 342 & 7.231 & 2.694 & 1.435 & 2.243 & 521 \\
\hline Ago & 3.233 & 4.033 & 81 & 983 & 1.410 & 5.642 & 903 & 2.480 & 2.062 & 1.064 & 2.330 & 737 \\
\hline Sep & 1.899 & 8.9 & 159 & 1.313 & 1.506 & 7.029 & 426 & 1.805 & 807 & 104 & 1.021 & 600 \\
\hline Oct & 1.965 & 10.030 & 175 & 97 & 2.986 & 7.087 & 98 & 589 & 885 & 0 & 1.526 & 1.633 \\
\hline Nov & 2.543 & 9.417 & 19 & 10 & 1.515 & 14.915 & 345 & 2.276 & 252 & 0 & 1.835 & 1.072 \\
\hline Dic & 3.496 & 10.160 & 74 & 134 & 748 & 7.900 & 261 & 1.668 & 329 & 503 & 1.826 & 1.582 \\
\hline 1918 & & & & & & & & & & & & \\
\hline Ene & 1.841 & 1.083 & 216 & 405 & 722 & 480 & 82 & 1.310 & 103 & 4 & 1.101 & 860 \\
\hline Feb & 1.146 & 1.5 & 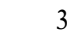 & 146 & 955 & 0 & 207 & 675 & 382 & 0 & 1.351 & 874 \\
\hline Mar & 83 & 5.427 & 58 & 0 & 948 & 3 & 42 & 469 & 883 & 101 & 1.273 & 2.324 \\
\hline$\Delta$ & 1.647 & 3.9 & , & 317 & 1.176 & 0 & 17 & 612 & - & 708 & 1.469 & 2.192 \\
\hline $\mathrm{M}$ & 1.8 & 4.7 & 103 & 0 & 398 & 277 & 100 & 1.406 & 334 & 282 & 1.157 & 6.258 \\
\hline Jun & 1.059 & 2.625 & 24 & 0 & 974 & 626 & 254 & 4.685 & 1.392 & 251 & 1.723 & 2.659 \\
\hline Jul & 1.373 & 4.0 & 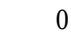 & & 518 & 1.915 & 29 & & 398 & 309 & 959 & 4.017 \\
\hline Ago & 1.057 & 11.73 & 4 & 1 & 231 & 480 & 47 & 6.021 & 341 & 4.754 & 1.300 & 799 \\
\hline Sep & 353 & 9.533 & 36 & 1 & 470 & 1.320 & 497 & 4.358 & 242 & 282 & 1.525 & 817 \\
\hline $\mathrm{Oc}$ & 2.451 & 1.7 & 10 & 1.317 & 1.401 & 1.0 & 89 & 4.357 & 99 & 2.604 & 1.504 & 2.180 \\
\hline No & 2.399 & 3.8 & 19 & 3.8 & 453 & & 48 & 5.461 & 713 & 3.544 & 2.121 & 2.115 \\
\hline Dic & 2.455 & 19.019 & 130 & 5.348 & 578 & 3.842 & 846 & 2.344 & 536 & 2.836 & 1.392 & 2.480 \\
\hline
\end{tabular}

Fuentes: Monthly Summary of Foreign Commerce of the United States (ene. 1917 - dic. 1918); Department of Commerce (1920).

Saliendo del problema puramente comercial, el gabinete español desplegó igualmente su diplomacia para preservar las otras fuentes de ingreso del país: los fletes y las remesas de trabajadores. La marina mercante española acumuló considerables beneficios durante los años de la guerra, interviniendo en el comercio con los países de la Entente. No obstante, este aumento de los ingresos vino parejo a un crecimiento considerable de los riesgos, ya que las embarcaciones del país se convirtieron en presa de los 
submarinos alemanes. Entre el hundimiento del Isidoro el 17 de agosto de 1915 y el del Villa de Solar el 26 de mayo de 1918, los sumergibles de Berlín echaron a pique ochenta y un barcos españoles, que sumaban un veinte por cien del tonelaje comercial disponible. En ese último año, el volumen de naves hundidas ascendió a 59.766 toneladas, que suponían un 35,5 por cien de las pérdidas sufridas por los mercantes hispanos durante la contienda. Las desmesuradas peticiones de tonelaje efectuadas por el Secretario de Estado coincidieron por tanto con uno de los momentos más críticos para los navieros españoles. Éstos habían ya efectuado diversas demandas de protección a las autoridades, y en algún momento llegaron a amenazar con paralizar el transporte comercial negándose a salir al mar. Parece natural que el gabinete decidiese evitar ulteriores complicaciones y resistir a toda costa las peticiones de Washington. Una actitud mantenida hasta que los negociadores norteamericanos alcanzaron el convencimiento de «la ausencia de un control real del gobierno sobre los navieros españoles». La manera en que Madrid respondió a la demanda de trabajadores españoles resulta también clarificadora de la posición adoptada por las autoridades. La necesidad de preservar la apariencia de una neutralidad estricta impedía al gobierno intervenir oficialmente en la contratación de ciudadanos españoles para servir a uno de los dos bandos. Ahora bien, la conciencia del valor económico de esos emigrantes temporales le llevó a allanar oficiosamente el camino para su traslado a Francia ${ }^{38}$.

Por otra parte, las instancias oficiales españolas pusieron su granito de arena a la hora de encontrar destino a los beneficios extraordinarios fruto de la guerra. Al considerar las relaciones con los Estados Unidos hemos podido acercarnos a dos de esos usos: la repatriación de la deuda pública en manos foráneas y la concesión de créditos a gobiernos extranjeros. La evolución de la primera de esas cuestiones se ajustó a la pauta apuntada en los trabajos de Albert Broder (1981, pp. 634-640). España había dado en 1914 los pasos legales necesarios para el retorno de su deuda exterior, dejando vía libre a su capitalización en pesetas y permitiendo su negociación en la bolsa de Madrid. Francia se resistió durante mucho tiempo a perder la posesión de esos títulos, haciendo que el montante de los valores españoles fuera de la Península apenas descendiera de 1.027,7 millones de pesetas en 1914 a 913,2 millones cuatro años después. Con todo, a la altura de 1918 las necesidades de liquidez de la Hacienda gala habían dejado a París con pocas armas para resistir las presiones hispanas. Sólo la intervención de Washington en las negociaciones permitió a los franceses mantener sus posiciones. No sería hasta después del armisticio cuando Francia se vio finalmente obligada a ceder ante las demandas Españolas, haciendo

${ }^{38}$ Fernández Almagro (1977, p. 264). Desp. de Palmer a Lansing, 22/8/1918. NARA, RG 84, Embassy Madrid, 1918. Davis y Engerman (2006, pp. 178, 180). Cunningham (1917, pp. 441442). Tel. 1.550, de Willard a Lansing, 15/7/1918. FRUS, 1918, Suppl. 1, vol. II, pp. 1.687-1.688. 
que el total de la deuda externa se redujera de 910,9 millones de pesetas en 1918, a 326,7 en 1919 y 169,8 en 1920. En lo referente a los préstamos, Young (1920, p. 9) ya anotó que «España, como los Estados Unidos, dejó de ser una nación deudora para convertirse en acreedora como consecuencia de la guerra». Los ingresos de los españoles colocaron a los banqueros nacionales en una posición que hizo posible prestar dinero a gobiernos extranjeros. Un proceso para el que la legislación exigía sanción oficial, y que dio a los gobiernos un papel crucial en las negociaciones financieras.

Las autoridades españolas jugaron a lo largo de 1917-1918 un papel de relevancia a la hora de mantener las condiciones que posibilitaban la bonanza en la balanza de pagos. La Primera Guerra Mundial había hecho crecer la dependencia comercial del país respecto de los Estados Unidos, y la entrada de éstos en la guerra puso por tanto en peligro la estabilidad de la economía española. Washington estableció una estrecha cooperación con los aliados e instauró un severo programa de embargos que pesó como una espada de Damocles suspendida sobre la cabeza de los gobiernos de Madrid. La presión norteamericana se dejó sentir especialmente a partir de comienzos de 1918, siendo una de las culpables de romper la dinámica de crecimiento experimentada por el comercio internacional de España desde el inicio de la contienda. Con todo, los gabinetes a las órdenes de Alfonso XIII supieron conservar una parte importante de las importaciones procedentes de Norteamérica, jugando con tres activos de especial relevancia. En primer lugar, la posición geográfica de la Península Ibérica, que la convertía en una plataforma idónea para abastecer a los ejércitos francés y estadounidense de unos productos que requerían cada vez con mayor urgencia. En segundo lugar, unos elevados beneficios acumulados durante la contienda, que colocaban a los banqueros españoles en posición de prestar dinero a los aliados. Gracias a ellos Francia obtuvo una ayuda vital a la hora de subsanar sus problemas de liquidez y los Estados Unidos pudieron detener la devaluación del dólar, que a partir del mes de agosto aumentó su cotización con respecto a la peseta. Por último, España poseía el intangible de la neutralidad, que colocaba a su favor el factor tiempo. Uno de los negociadores norteamericanos comentó en un momento dado que «la gente no está aquí hecha para las prisas». Sin embargo, las dilaciones de los ministerios españoles pudieron ser una consecuencia no tanto del carácter intrínseco de los habitantes del país, como de una estrategia premeditada. Los dirigentes hispanos habían de ser conscientes de que mientras la guerra siguiera su curso las necesidades de los aliados adquirían una mayor urgencia, en tanto que España, si bien sometida a una cierta premura, podía disponer en todo momento de un mayor colchón de tiempo. Pese a todo, los líderes españoles no pudieron respirar con total alivio hasta que el 29 de 
noviembre de 1918, una vez firmado el armisticio, el WTB decidió que «en el futuro la AEF requerirá poco de España, y no será necesario seguir reteniendo mercancías al objeto de ejercer presión» ${ }^{39}$.

\section{FUENTES}

Archives Diplomatiques - Ministère des Affaires Étrangères (AD-MAE), París (Francia): Nouvelle Série. Série A. Guerre, 1914-1918.

Archivo General de la Administración (AGA), Alcalá de Henares (España): Asuntos Exteriores. Embajada de España en los Estados Unidos.

Archivo Histórico del Ministerio de Asuntos Exteriores (AMAE), Madrid (España): Archivo Histórico. Política. Estados Unidos.

Library of Congress - Manuscript Division (LOC), Washington DC (EEUU): Chandler P. Anderson Papers.

Willard Family Papers.

National Archives and Records Administration (NARA), College Park (Maryland, EEUU):

Record Group 59: Central Files of the Department of State, 1910-1929.

Record Group 84: Foreign Service Post Files. Embassy Madrid.

\section{BIBLIOGRAFÍA}

Bailey, T. A. (1966): The Policy of the United States Towards the Neutrals. Gloucester: Peter Smith.

Bliven, B. (1928): «Charles G. Dawes, Super-Salesman». New Republic 53 (686), pp. 263-267.

Broder, A. (1981): «Le Rôle des intérêts étrangers dans la croissance économique de l’Espange, 1768-1924». Paris: Université Paris I, Thése de Doctorat d'État.

Collins, Th. M. (2002): Otto Kahn: art, money \& modern time. Chapel Hill: University of North Carolina Press.

Cunningham, Ch. H. (1917): "Spain and the War». The American Political Science Review 11 (3), pp. 421-447.

DalleK, R. (1975): Franklin D. Roosevelt and American Foreign Policy. New York: Oxford University Press.

Davis, L. E., y Engerman, S. L. (2006): Naval Blockades in Peace and War. An Economic History since 1750. New York: Cambridge University Press.

Delaunay, J.-M. (1984): «Les crédits Urquijo et la France en guerre». Mélanges de la Casa de Velazquez 20, pp. 339-353.

Department of Commerce (1917): Foreign Commerce and Navigation of the United States in the fiscal year 1917. Washington DC: Government Printing Office.

- (1920): Statistical Abstract of the United States. 1919. Washington DC: Government Printing Office.

Fernández Almagro, M. (1977): Historia del reinado de Alfonso XIII. Barcelona: Montaner y Simón.

39 Tel. 5, de Willard a Sharp, 20/1/1918. NARA, RG 84, Embassy Madrid, 1918. Tel. 1.858, de Lansing a Willard, 29/11/1918. NARA, RG 59, 1910-1929, 652.119/2246. 
FERRo, M. (1994): La Gran Guerra (1914-1918). Madrid: Alianza.

GoedeKen, E. A. (1986): «Charles G. Dawes and the Military Board of Allied Supply». Military Affairs 5 (1), pp. 1-6.

Kaufman, B. A. (1974): Efficiency and Expansion. Foreign Trade Administration under the Wilson Administration. Westport: Greenwood Press.

Kennedy, D. M. (1980): Over Here. The First World War and American Society. New York: Oxford University Press.

Maluquer, J. (2005): «Consumo y precios», en A. Carreras y X. Tafunell (coords.): Estadísticas Históricas de España: siglos XIX y XX. Bilbao: Fundación BBVA, vol. 3 , pp. 1.246-1.295.

Martín ACEÑA, P., y Pons, M. ${ }^{\text {a }}$ A. (2005): «Sistema monetario y financiero», en A. Carreras y X. Tafunell (coords.): Estadísticas Históricas de España: siglos XIX y XX. Bilbao: Fundación BBVA, vol. 3, pp. 644-706.

Pershing, J. J. (1995): My Experiences in World War I. New York: Da Capo Press, 2 vols. Roldán, S. y GARCía DELGADO, J. L. (1973): La consolidación del capitalismo en España, 1914-1920. Madrid, Confederación Española de Cajas de Ahorros.

SAN ROMÁN, E. (1994): «Las consecuencias pacíficas de la Gran Guerra: La movilización industrial». Hispania 54 (187), pp. 611-658.

- (1999): Ejército e Industria: El nacimiento del INI. Barcelona: Crítica.

SUDRIÀ, C. (1990): «Los beneficios de España durante la Gran Guerra. Una aproximación a la balanza de pagos española, 1914-1920». Revista de Historia Económica 8 (2), pp. 363-396.

Tena Junguito, A. (1985): «Una reconstrucción del comercio exterior español, 1914 1935: La rectificación de las estadísticas oficiales». Revista de Historia Económica, 3(1), pp. 77-119.

- (1992): Las Estadísticas Históricas del Comercio Internacional: Fiabilidad y Comparabilidad. Madrid, Banco de España.

- (2005): «Sector Exterior», en A. Carreras y X. Tafunell (coords.): Estadísticas Históricas de España: siglos XIX y XX. Bilbao: Fundación BBVA, vol. 2, pp. 573- 644.

VANDELlós, J. A. (1931): «La balanza comercial y el cambio de la peseta». Revista Nacional de Economía 32, pp. 3-17.

Whiteman, H. B. (1958): «Norman H. Davis and the search for international peace and security, 1917-1944». New Haven: Yale University, Ph. D. dissertation.

Woolsey, T. S. (1917): «The Rationing System». The American Journal of International Law 11 (4), pp. 844-847.

Young, A. N. (1920): Spanish Finance and Trade. Washington DC: Government Printing Office. 
DIPLOMACIA ECONÓMICA Y BALANZA DE PAGOS. LOS PACTOS HISPANO...

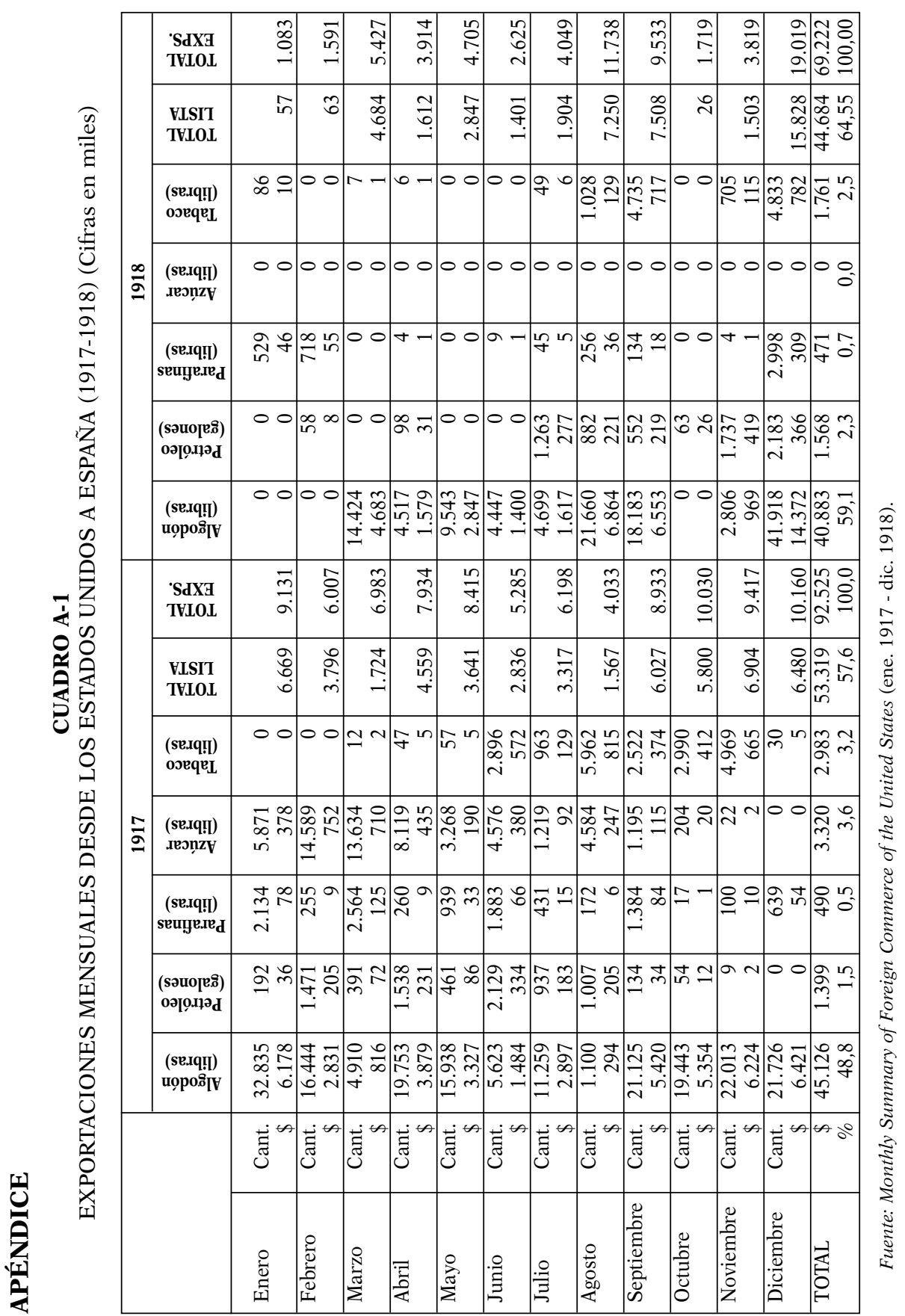


